Portland State University

PDXScholar

Spring 7-26-2018

\title{
Bystander Intervention to Prevent Campus Sexual Violence: the Role of Sense of Community, Peer Norms, and Administrative Responding
}

Erin Christine McConnell

Portland State University

Follow this and additional works at: https://pdxscholar.library.pdx.edu/open_access_etds

Part of the Psychology Commons

Let us know how access to this document benefits you.

\section{Recommended Citation}

McConnell, Erin Christine, "Bystander Intervention to Prevent Campus Sexual Violence: the Role of Sense of Community, Peer Norms, and Administrative Responding" (2018). Dissertations and Theses. Paper 4554.

https://doi.org/10.15760/etd. 6439

This Thesis is brought to you for free and open access. It has been accepted for inclusion in Dissertations and Theses by an authorized administrator of PDXScholar. Please contact us if we can make this document more accessible: pdxscholar@pdx.edu. 


\title{
Bystander Intervention to Prevent Campus Sexual Violence:
}

The Role of Sense of Community, Peer Norms, and Administrative Responding

\author{
by \\ Erin Christine McConnell
}

Thesis defense submitted in partial fulfillment of the requirement for the degree of

\author{
Master of Science \\ in \\ Psychology
}

\author{
Thesis Committee: \\ Keith Kaufman, Chair \\ Eric Mankowski \\ Greg Townley
}

Portland State University

2018 


\begin{abstract}
In recent years, the use of bystander intervention training to address campus sexual violence has risen rapidly. More research is critically needed to guide the ongoing development and implementation of prevention efforts by campuses utilizing this relatively new approach. This investigation examined associations between college students' bystander intervention behavior and three key factors: (1) perceived peer norms supportive of sexual violence; (2) perceived campus administrative response to sexual violence; and (3) sense of campus community. Data from a sample of 2370 college students was analyzed using hierarchical linear regression to test both direct and moderated effects. Findings revealed that both peer norms supportive of sexual violence and perceptions of campus administrative response to sexual violence were significantly associated with bystander intervention. No significant direct or moderating effects related to sense of campus community were uncovered in this sample. Implications of this study include contributing to the current knowledge base about factors associated with bystander intervention behavior, and informing campus efforts to make bystander training programs more effective.
\end{abstract}




\section{Table of Contents}

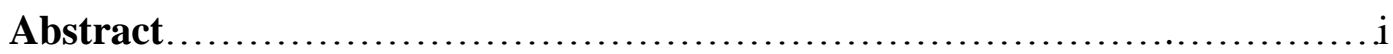

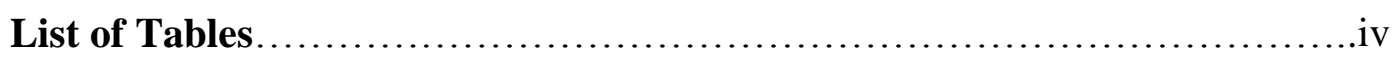

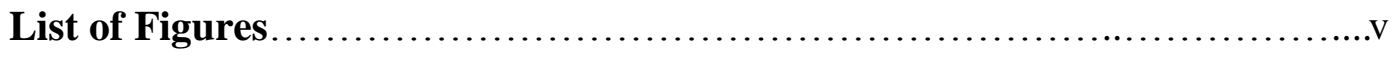

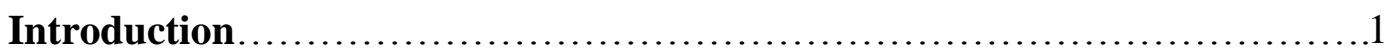

Campus Sexual Violence and Bystander Intervention...................4

Sexual Violence Terminology...................................4

Campus Sexual Violence.........................................6

Prevalence.....................................................

Institutional Outcomes...........................................

Traditional Prevention Approach...................................8

The Bystander Intervention Approach...............................8

Public Health Model............................................... 9

Indications of Effectiveness...................................10

Bystander Theory and Literature Review............................. 12

Barriers to Bystander Intervention..............................15

Social Norms ................................................. 15

Sense of Community......................................... 16

Literature Critique Summary....................................23

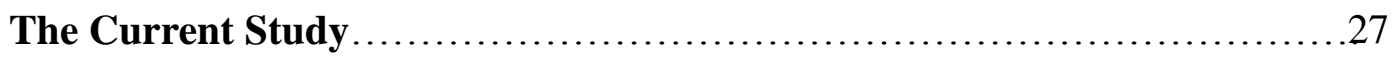

Study Purpose, Research Questions, and Hypotheses...................29

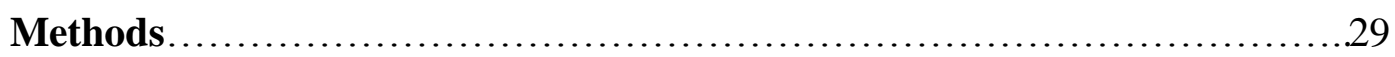

Participants....................................................... 33 
Demographics Variables.........................................33

Measures...........................................................

Study Design and Procedure....................................... 37

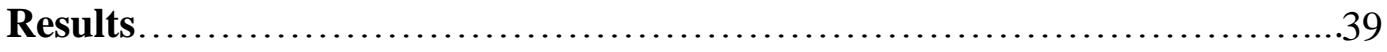

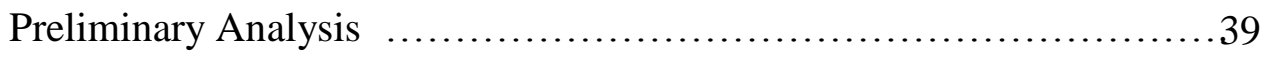

Inferential Analysis.........................................41

Exploratory Analysis........................................44

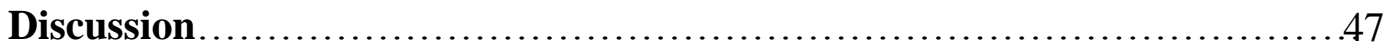

Peer Norms Supportive of Sexual Violence.........................47

Perceptions of Campus Response to Sexual Violence.................49

The Role of Sense of Campus Community.........................51

Bystander Opportunity......................................52

Limitations.................................................54

Conclusion.......................................................57

References...................................................66

Appendix A. Measures...............................................76 


\section{List of Tables}

\section{Table 1}

Descriptive Statistics. .58

Table 2

Control Variables.

Table 3

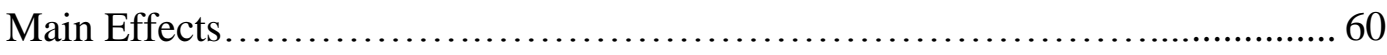

\section{Table 4}

Moderating Effects of SOC with Peer Norms...............................61

\section{Table 5}

Moderating Effects of SOC with Perceptions of Admin Response..............62

\section{Table 6}

Relation of Study Variables with N/A Response 


\section{List of Figures}

\section{Figure 1}

Descriptive Statistics..................................................64

Figure 2

Control Variables.........................................................65 


\section{Introduction}

Sexual violence is a serious public health issue with far reaching consequences. Millions of individuals from all backgrounds and circumstances are sexually victimized each year across the United States, but notably high are the rates among college student populations (Black et al., 2011; CDC, 2014; Fisher, Cullen \& Turner, 2000). In recent years, bystander intervention training has become perhaps the most favored approach used by colleges and universities to address campus sexual violence (McMahon, 2015). As bystander intervention becomes more pervasive, continued research is needed to determine how this relatively new strategy can be refined and expanded upon to increase efficacy. Using a novel moderation approach, this study investigated the importance of three factors relevant to Bystander Theory: (1) perceived peer norms supportive of sexual violence; (2) perceived campus administrative response to sexual violence; and (3) sense of campus community.

The general aim of bystander intervention training on college campuses is to increase students' awareness of risky situations and their opportunities for intervening, as well as to help students develop and practice skills for safely defusing those situations before they escalate (McMahon, 2015). While individual skills and knowledge about how and when to intervene are important, they may not be sufficient for helping college students overcome many of the barriers to intervention that social and community factors can present. For instance, a large amount of research has demonstrated that perceived peer attitudes and behaviors - frequently referred to as "peer norms"-are strongly linked to bystander intervention behaviors (e.g., Fabiano, Perkins, Berkowitz, Linkenbach, \& 
Stark, 2003). Accordingly, most bystander intervention training programs now incorporate approaches specifically aimed at improving peer norms.

While the peer norms approach has garnered considerable attention in bystander intervention research and practice, peers represent only one of many possible sources of social influence. In actuality, it is likely that multiple referent groups simultaneously influence individuals' behavior (Taylor \& Todd, 1995). There is a paucity of research exploring the role of college students' perceptions of influential social bodies other than peers in determining their bystander intervention behaviors, including perceived normative attitudes and behaviors of campus administration regarding issues of sexual violence. Furthermore, since peer groups, as well as campus administrations, are both key facets of college students' campus communities, it stands to reason that the impact of either on bystander intervention might depend on how strongly connected students feel to that community—or in other words, their sense of campus community. This line of reasoning has yet to be empirically investigated.

The current study fills a significant gap in the literature by shedding light on the nature of the relationship between college students' bystander intervention behavior, their perceptions of peer norms and campus administrative response, and their sense of campus community. This investigation contributes to the current knowledge base on the association between each of the abovementioned factors and bystander intervention behavior to prevent campus sexual violence. Additionally, findings may be used to inform the ongoing development and improvement of campus-based bystander intervention training programs as well as the practices supporting those programs. 
The sections below begin by providing background information related to campus sexual violence and bystander intervention training programs, and includes key terminology and theories. Next, the constructs of bystander intervention, peer norms, administrative response, and sense of community are discussed in relation to theory and previous research relevant to the current study. The research questions, hypotheses, and methodology are outlined, followed by a detailed description and interpretation of the results. Finally, a concluding discussion addresses study implications, limitations, and future directions. 


\section{Background: Campus Sexual Violence and Bystander Intervention}

This introductory section begins by defining key sexual violence terminology. Next, it provides a brief overview of campus sexual violence, its consequences, and traditional approaches to prevention. Then, the bystander intervention training approach is described, and framed within the public health prevention model. This section concludes by presenting some of the promising results of campus bystander intervention program evaluations, while also revealing the need for further research in this area.

\section{Sexual Violence Terminology}

When discussing any topic related to sexual violence, it is important to establish a shared vocabulary. This is crucial since "sexual violence" and many related terms have multiple definitions associated with them, some legal (which can vary by state and/or country), and some colloquial (which can vary by user and/or context). Thus, the definitions provided below are by no means universal, but are intended to foster an understanding of how key terms are used within this document.

"Sexual violence" is generally thought of as a non-legal term referring to a broad range of unwelcome sexual behaviors. The spectrum of sexual violence includes any completed or attempted sexual intercourse or sexual touching without the consent of all those involved. Sexual violence also includes unwanted sexual comments, advances, or harassment (Krug, Mercy, Dahlberg, Zwi, \& Lozano, 2002). Non-contact/non-verbal forms of sexual violence can include voyeurism, unwanted sexual emails or texts, or persistent and uncomfortable sexual staring (Koss, Wilgus, \& Williamsen, 2014). Sexual violence can occur in any setting, including residences, schools, or workplaces. Two 
categories often used to characterize different forms of sexual violence are "sexual assault" and "sexual harassment," which are each defined below.

"Sexual assault" is a term used for sexually violent acts where invasive physical contact occurs between a victim ${ }^{1}$ and perpetrator. Sexual assault includes any nonconsensual penetration, fondling, or touching. These can be acts that are forced onto a non-consenting person's body, or that a non-consenting person is made to perform on a perpetrator's body. Sexual assault is committed through coercion (Krug et al., 2002). The term "coercion" covers a range of degrees and types of force. Examples of coercive force include physical harm, threats of physical harm, psychological intimidation, blackmail, or other threats related to losing something of value (e.g., a job or promotion, child custody, housing, etc.). Coercion is also considered to occur when the person being sexually aggressed upon is not capable of giving their consent, such as if they are drunk, asleep, drugged, under the consenting age, or lack the mental capability to understand all aspects of the situation (Krug et al., 2002).

"Sexual harassment" is used to describe acts of sexual violence that do not "rise to the level of sexual assault" (Bhargava \& Jackson, 2013, p. 2). Sexual harassment can be physical, but is usually considered more ambiguous than sexual assault, and occurs such that a pattern develops over time (e.g., a co-worker who regularly solicits unwanted hugs, or frequently touches a person's leg or shoulder when talking to them, despite a lack of returned affection). Sexual harassment is often non-contact, such as offensive sexist

\footnotetext{
${ }^{1}$ The terms "victim" and "survivor" are used interchangeably throughout this document. Usually, "victim" is used to describe sexual violence acts (either planned, or carried out). "Survivor" is used to discuss the short- and long-term effects of sexual violence, and in reference to a person who has endured past sexual violence. Attempts are made to use person-first terminology. Please note that, while not applicable to the current document, this author supports the use of language chosen by the individual to describe their personal experiences.
} 
remarks, sexually crude gestures, or sexual leering. Sexual harassment is not always directed at a specific person; for example, it might take the form of sexist comments about women in general. The result of sexual harassment is often a social climate that feels hostile, intimidating, or offensive to one or more person (Koss et al., 2014).

Very often, sexual violence manifests as subtle expressions of negative or sexist attitudes about women, which are called "micro-aggressions." While sexual microaggressions can be commonplace, and are often ignored and/or considered innocuous, the stress caused by them may be chronic and cumulative, and lead to mental health issues such as depression and anxiety (Gartner \& Sterzing, 2016). In addition, micro-acts of sexual violence are thought to be a large contributing factor in shaping cultural tolerance of sexual violence across the spectrum (McMahon \& Banyard, 2012). In this way, subtler wide-spread forms of sexual violence (such as cat-calling, or sexist jokes) can facilitate higher-severity forms (such as rape, or other types of sexual assault; Gartner \& Sterzing, 2016). Indeed, sexual violence acts across the spectrum are thought to be mutually reinforcing. Similarly, preventing sexual violence at one point in the continuum can have impacts on behaviors across the continuum (McMahon \& Banyard, 2012).

\section{Campus Sexual Violence}

Campus sexual violence is defined as any act of sexual violence either committed by, or perpetrated against, a college student, regardless of the location where it occurs. While there is no way of knowing precisely how many college students endure sexual assault and/or sexual harassment, perhaps the best available estimates for the current scope of the problem come from a 2015 survey conducted by the Association of American Universities (AAU). 
Prevalence. The investigation of campus sexual violence by the AAU sampled 779,170 students (i.e., who were all enrolled at the time of the study) from 27 colleges and universities, and obtained 150,072 responses (a response rate of 19.3 percent; Cantor et al., 2015). The study found that approximately twenty-three percent (23\%) of undergraduate women and eight percent (8\%) of undergraduate men had experienced some form of unwanted physical sexual contact since the beginning of their college tenure (Cantor et al., 2015). This nonconsensual contact ranged from kissing and groping to penetration, and was obtained through force, threats, and/or incapacitation. When noncontact acts of sexual harassment were included in the calculation of sexual violence frequency, Cantor et al. (2015) found that none of the 27 universities had a prevalence rate lower than $49 \%$ among surveyed women. This study also highlighted how infrequently the crime of campus sexual assault is reported. Only about 1 in 4 survivors of sexual assault surveyed in the AAU study said that they made any report of the incident, either to their school or to law enforcement (Cantor et al., 2015).

Survivor Outcomes. Campus sexual violence has the potential to seriously impact many different aspects of a survivors' life. Sexual assault is associated with adverse academic, psychological, behavioral, and physical outcomes for survivors, as exemplified by the following studies. In terms of academic consequences, Mengo and Black (2015) found significant declines in college students' GPAs following a sexual assault experience. The same study also revealed that, compared to the general student population, students who reported being sexually assaulted while enrolled in college had significantly higher rates of college drop-out (Mengo \& Black, 2015). One investigation of the mental health outcomes for survivors found a positive association between the 
number of sexual assaults experienced after the age of 17 and college women's scores on a measure of posttraumatic stress (Borja, Callahan, \& Long, 2006). Behaviorally speaking, Turchik and Hassija (2014) observed that college women who had been sexually victimized after the age of 16 were more likely than their (non-victimized) peers to engage in problematic drinking, drug use, and sexual risk taking, and also were more likely to experience symptoms related to sexual dysfunction. The physical consequences of sexual assault, specifically in college populations, is an understudied area. In the general population, however, research suggests that having a history of sexual assault is associated with poorer physical health status (Golding, 1999), and also with more chronic medical conditions (Ullman \& Brecklin, 2003).

Institutional Outcomes. While the need to protect students from harm may constitute the strongest ideological argument in favor of increasing sexual violence prevention, campuses may be compelled by more commercial reasons. For instance, a recent report by United Educators (2015) looked at the economic costs of sexual violence for colleges and universities. The report, which reviewed 1000 campus sexual assault proceedings, found that when cases included litigation proceedings, claims against institutions averaged $\$ 350,000$, and ranged as high as $\$ 2$ million. Additionally, campus sexual assault occurrences can lead to bad publicity for universities, which in turn may result in a drop in student applications (Luca, Rooney, \& Smith, 2017). Clearly, preventing instances of campus sexual assault is a critical step, and one from which both students and campus administrations stand to benefit.

Traditional Prevention Approach. Over the past several decades, colleges and universities have taken a number of different approaches to sexual assault prevention. 
Traditionally, efforts have focused on teaching college women (i.e., the implied victims) strategies for defending themselves and making themselves less vulnerable. This often included advising women to dress conservatively, not to drink too much, to travel in groups, and to avoid being out late at night (Banyard, Moynihan, \& Plante, 2007). Men

on the other hand (i.e., the implied perpetrators), were traditionally taught about the legal consequences that they could face if caught perpetrating sexual assault. This approach essentially allowed male students to disengage from the broader issues of sexual violence if they believed that they themselves would not commit rape; a belief which is true for the majority of men (Banyard et al., 2007). These outmoded practices have been criticized for perpetuating 'victim-blaming' and 'male-bashing,' and ultimately, the problem of sexual assault on college campuses has persisted.

\section{The Bystander Intervention Approach}

In recent years, bystander intervention has garnered increasing attention for its potential to prevent sexual violence, and has become a central part of many campuses' prevention efforts. Bystander intervention models encourage everyone to participate in prevention in a positive way, presenting a more appropriate way of engaging students than the traditional methods of casting them as either victims or perpetrators (Banyard, 2015).

A "bystander" is defined as any third-party person who is neither a perpetrator nor a subject of sexual violence, but who witnesses concerning behavior(s) related to sexual violence (Powell, 2011). When a bystander steps in to help in some way, they are called an "active" or a "prosocial" bystander. On the other hand, a bystander who takes no action to help the situation is considered a "passive" bystander (Fenton, Mott, McCartan, 
\& Rumney, 2016). As a prevention strategy, the bystander intervention approach works when active third-party behaviors remove or reduce the threat of harmful outcomes related to sexual violence (Banyard, Plante, \& Moynihan, 2004).

Opportunities for college students to intervene as active bystanders may be very common. Using data collected by the National Crime Victimization Survey between 1993 and 1999, Planty (2002) found that a third-party person (i.e., a person who was neither a victim nor a perpetrator) was present during $29 \%$ of all sexual assaults on record. Bystander intervention training provides students with the skills and knowledge to take positive intervention actions before, during, or after an incident of sexual assault (McMahon \& Banyard, 2012). This means that a single sexual assault case is likely to present multiple bystanders with a number of opportunities to intervene, and that intervention opportunities likely exist in a percentage of sexual assaults much larger than $29 \%$ (perhaps even in the majority of cases).

Intervention opportunities are, of course, not limited to those times when sexual assault is an eminent threat, but include situations that fall anywhere along the sexual violence continuum. Below, bystander intervention is examined from a public health standpoint, and further considered in terms of higher-risk or lower-risk situations.

Public Health Model. Just as it sounds, "public health" is mainly concerned with promoting healthful outcomes at the population (or community) level, rather than at the individual level alone. Consequently, the public health approach emphasizes prevention efforts that engage the entire community, rather than just those individuals considered "at risk." In terms of sexual assault prevention, the public health approach works by creating societal conditions which protect against sexual assaults (i.e., while encouraging positive 
interpersonal behaviors). Campus bystander intervention programs embrace these principles by encouraging community involvement in preventing sexual assault, and by helping to shape community norms that are less tolerant of sexual violence.

There are three types of prevention recognized within public health: primary, secondary, and tertiary. In relation to bystander intervention, these can be thought of as interventions that occur before (primary), during (secondary), or after (tertiary) an act of sexual violence. Although bystander intervention training touches on each prevention level, it generally concentrates on primary prevention. This is in accordance with the public health approach, which emphasizes that primary prevention efforts simultaneously reduce the need for secondary and tertiary prevention (CDC, 2004).

Within primary prevention, bystander intervention situations can be thought of as ranging from relatively low-risk to relatively high-risk (McMahon \& Banyard, 2012). High-risk primary prevention situations are those with the most potential to cause immediate and severe harm. This includes any situation likely to result in sexual assault and/or rape. For example, a drunk woman passed out on a couch at a party who is being approached or touched by a man or group of men would constitute a high-risk situation (McMahon \& Banyard, 2012). Another high-risk situation might be a college student telling a friend about his plan to get a woman intoxicated in order to have sex with her. A low-risk primary prevention situation, on the other hand, is one where concerning attitudes related to sexual violence surface, but there is no immediate or severe threat of an individual being harmed. For example, conversations which include sexually derogatory jokes, victim-blaming, or rape-myths could be considered low-risk situations (McMahon \& Banyard, 2012). 
According to a study by McMahon, Postmus, and Koenick (2011), college students tend to be more willing to intervene as bystanders in high-risk situations than in low-risk ones. The authors speculate that, while students recognize very overt sexual violence as intervention appropriate, they fail to see acts across the continuum of sexual violence as problematic. Further, students may not understand the linkages between acts of sexual violence across the continuum (i.e., that relatively minor or subtle acts of sexual violence influence the occurrence of more overt acts of sexual violence, and vice versa; McMahon et al., 2011). Bystander intervention training programs have begun to address this gap in college students' awareness regarding the interrelated nature of the spectrum of sexual violence, and to teach intervention techniques for both low-risk and high-risk situations (e.g., New York State Department of Health, 2013).

Indications of Effectiveness. In 2014, the White House Task Force to Protect Students from Campus Sexual Assault released its first report, which highlighted bystander intervention training as a "promising strategy." The report, however, also acknowledged that better empirical evidence was needed to evaluate the efficacy of bystander training programs (CDC, 2014). Although research is still limited, several studies have since been published looking at the impact of bystander intervention training on sexual violence at the campus-community level.

A multi-year evaluation of "Green Dot" (a particularly widely-used campus bystander intervention program) published in 2015 found that, compared to two demographically similar non-intervention control campuses, an intervention campus had lower rates of both sexual violence victimization and perpetration (17\% and $21 \%$ reductions, respectively) when combining unwanted sex, sexual harassment, stalking, and 
physical and psychological violence (Coker et al., 2016). When Coker et al. (2016) looked specifically at sexual assault, however, only rates of victimization, and not perpetration, were significantly lower on the intervention campus. An investigation of the "Bringing in the Bystander" program utilized a randomized control trial design and a one year follow-up (Moynihan et al., 2015). This study found that college students who participated in this 4.5 hour program reported engaging in more bystander helping behavior directed toward friends, but unfortunately not strangers, at follow-up compared to the control group (Moynihan et al., 2015). These generally positive findings, along with other similar findings (e.g., see Senn \& Forest, 2015), justify the continued use and development of bystander approaches by campuses seeking to address sexual violence. At the same time, they reveal room for improvement, and the need for more research in this area.

Given the serious consequences of sexual violence for college students, there is much to be gained by maximizing the success of bystander programs, and ultimately inspiring a wider student population to offer more helping behaviors to a broader campus community. To that end, it is important to understand why active bystanders decide to intervene, and what barriers can cause them to remain passive. In her 2015 article, "Call for research on bystander intervention to prevent sexual violence: The role of campus environments," Sarah McMahon identified several promising areas of research which are in need of further investigation and which could provide crucial information for the development of bystander intervention training. If left unaddressed, there is a risk that these gaps will undermine the viability of the bystander intervention approach to prevention on college campuses. 
In the following section, barriers to bystander intervention are discussed, as well as the current literature related to three of those factors suggested by McMahon (2015), namely: (1) peer norms supportive of sexual aggression; (2) campus administrative response to sexual violence; and (3) sense of campus community. 


\section{Bystander Theory and Literature Review}

This section begins by outlining a model of common barriers to bystander intervention. It then introduces social norms theory, and reviews the bystander intervention literature related to peer norms and campus administrative response to sexual violence. Next, sense of community is discussed along with a review of the relevant literature. The section concludes with a critique of the literature which highlights the need for the current study.

\section{Barriers to Bystander Intervention}

To understand why some bystanders take prosocial action while others remain passive, the present study is informed by Latané and Darley's (1970) well-known situational model of bystander intervention, and by Shawn Burn's (2009) application of that model to sexual violence prevention. According to these authors, there are five steps that necessarily precede any effective bystander action. In order for an intervention to be successfully executed, a bystander must: (1) notice the event or situation occurring; (2) recognize the situation as problematic; (3) feel like they have a responsibility to intervene; (4) decide how they could help; and finally, (5) act to intervene (Burn, 2009; Latané \& Darley, 1970). Failure to progress at any of these steps results in a barrier to successful bystander intervention.

In many ways, bystander intervention training programs are designed to help students overcome each of the five-step's major barriers. Students are taught to identify risky situations and intervention opportunities, which can help them to overcome the barriers associated with steps one and two; namely, the failure to notice and the failure to identify a situation as intervention appropriate barriers. Students are encouraged to take 
responsibility for intervening, which comes across even in the names adopted by some of the programs (e.g., It's on Us, and Men can Stop Rape), helping to address the step three barrier, failure to take responsibility. Participants practice using different strategies for safely diffusing a variety of risky situations, preparing them to overcome the step four and five barriers, failure to decide how to help and failure to act.

While it is clear that a large focus of bystander intervention training is on improving individual skills and knowledge, these five barriers are also related to social and situational factors, such as the presence of other bystanders, perceptions about normative attitudes and behaviors, and the relationship of the bystander to the potential victim or perpetrator. In their review chapter, Encouraging bystander intervention for sexual violence, Foubert, Tabachnick, and Schewe (2010) conclude that an important avenue for the prevention of sexual violence involves shifting broader social and community norms in ways that support bystander intervention. The following sub-section delves into social norms theories and research related to bystander intervention.

\section{Social Norms}

Social norms are informal "rules and standards that are understood by members of a group, and that guide and/or constrain social behaviors without the force of laws" (Cialdini \& Trost, 1998). Social norms function to either encourage or inhibit interpersonal behaviors, including prosocial bystander intervention (Berkowitz, 2010). Individuals may use their perceptions of social standards to help them determine whether or not a given situation calls for an intervention. When people believe they have the support of others, they are more likely to behave in prosocial ways, including by actively intervening as bystanders to diffuse risky situations (Berkowitz, 2010). The perception 
(even if incorrect) that an intervention would not be supported by others can cause two types of barriers to intervention. First, bystanders might be led to believe that their desire to intervene must be misplaced. This phenomenon is called "pluralistic ignorance," and can lead to the failure to identify a situation as intervention appropriate barrier (Latané \& Darley, 1970). Second, bystanders might feel audience inhibition, which can result in a failure to act due to fears of being embarrassed or socially sanctioned.

The influence of perceived norms on bystander behavior can be further understood using Ajzen and Fishbein's theory of reasoned action (TRA; 1980) and Ajzen's theory of planned behavior (TPB; 1988). These theories posit that a person's perceptions of social norms influence their intention to behave in ways that align with those norms, to the extent that the person is motivated to comply with the beliefs of their normative referent group. Expanding on this, Taylor and Todd (1995) propose a "decomposed" structure for normative beliefs in the TPB and TRA, suggesting that the perceived norms of multiple referent groups can simultaneously influence behavioral intention. Social norms research with adolescent populations has overwhelmingly focused on two main referent groups: peers and parents (e.g., Baker, Little, \& Brownell, 2003; Kandel, 1973). Often, studies have concluded that peer influence increases with age while parental influence decreases (Scalici \& Schulz, 2017). For college students, campus administration might emerge as a new source of normative influence, being relatively proximal to (on-campus) students, and representing what is likely to be an important in-group for students: their campus community. 
The following two subsections summarize literature related to the normative influence on bystander behavior of two potentially significant referent groups for college students: peers, and campus administration.

Peer Norms. Peers represent perhaps the most important referent group for college students (Taylor \& Todd, 1995). Although the majority of research on the role of peer norms in campus sexual violence prevention focuses on reducing perpetration behaviors (e.g., DeKeseredy, Schwartz, \& Alvi, 2000; Schwartz \& DeKeseredy, 1997; Schwartz, DeKeseredy, Tate, \& Alvi, 2001), a growing body of research supports the idea that perceived peer norms have a substantial impact on bystander's willingness to intervene (see McMahon, 2015, for a review). This can be viewed as problematic, considering that research also suggests that college men in particular tend to hold significant negative misperceptions when it comes to their male peers' attitudes and beliefs. For example, Stein (2007) found that male college students perceived their peers' attitudes toward sexual violence and bystander intervention as significantly less prosocial than their own personally held attitudes. Furthermore, perceived peer willingness to intervene significantly predicted students' own willingness to intervene (Stein, 2007). An investigation by Fabiano et al. (2003) came to a similar conclusion. They found that college men's actual attitudes about the importance of sexual consent, as well as their own willingness to intervene to stop sexual violence, were significantly greater than their guesses about how their peers would respond. Again, perceptions of male peers' willingness to help as bystanders significantly predicted male participants' own willingness to help (Fabiano et al., 2003). However, one study by Brown, Banyard, and Moynihan (2014) found support for their hypothesis that peer norms supportive of 
bystander intervention would be significantly associated with college students' bystander intentions, but failed to find the hypothesized association between peer norms and actual self-reported bystander intervention behaviors (i.e., those that had been performed during the previous college semester).

Perceived peer attitudes regarding sexual violence has been suggested as an important variation of peer norms which should be considered for its role in determining bystander intervention behavior; however, a limited number of studies have directly investigated this association (McMahon, 2015). One study by Orchowski, Berkowitz, Boggis, and Oesterle (2016) found that men's perceived peer approval of sexual aggression was associated with lower prosocial bystander intervention attitudes. Even more strikingly, a study by Brown and Messman-Moore (2010) found that men's perceptions of peer support for sexual aggression was a better predictor of their willingness to intervene than even their own, personally-held attitudes about sexual aggression. However, one study by Banyard and Moynihan (2011) found that in a sample of 406 male and female college students, freshman who perceived their peers as more supportive of sexual coercion also reported having performed significantly more prosocial bystander behaviors related to sexual violence in the past two months. For sophomores, juniors, and seniors the association was non-significant, but in the expected (negative) direction.

One possible explanation for Banyard and Moynihan's (2011) unexpected findings is that with peer norms more supportive of sexual coercion comes a higher likelihood of encountering intervention opportunities. Freshmen students may tend to take greater advantage of those intervention opportunities compared to more advanced 
students, perhaps due to having a stronger sense of campus in-group membership (Banyard \& Moynihan, 2011). Freshmen are highly motivated to integrate into their new community, are more likely to live on-campus, and spend more time attending campus activities and events, all of which may contribute to greater feelings of connection to the campus at large. This heightened sense of campus community could contribute to their willingness to intervene in order to help other members of that community (or the community as a whole) when the opportunities arise, despite their perceived peer attitudes. In terms of the TRA and the TPB, it may be that students with a greater sense of campus community feel less motivated to behave in accordance with a perceived norm if doing so would be damaging in some way to their campus community. The importance of this felt connection to the campus community as it relates to bystander intervention is explored later, in the sense of campus community sub-section.

Although the role of peer norms in sexual violence bystander intervention has received a fair amount of research attention, a number of limitations in the current knowledge base remain. First, the majority of research has focused only on male student populations. Second, most studies have used bystander intervention intentions (or willingness to intervene) as the outcome variable of interest, rather than actual bystander behaviors. When bystander behavior has been examined, results have been more varied and the impact of peer norms has been less clear (e.g., Banyard \& Moynihan, 2011; Brown et al., 2014). While some of this ambiguity is likely due to the difficulty of assessing missed versus acted upon bystander opportunities, it also suggests the need to examine other moderators, including students' sense of campus community. 
Campus Administrative Influence. Peers are not the only group that college students may look toward as normative models when it comes to developing their behavior and belief systems. While parents may no longer serve as salient referents, Sarah McMahon (2015) and others (e.g., Banyard, 2011; Sulkowski, 2011) have suggested that another important source of influence for college students might come from campus authority figures, including administrative bodies. However, no empirical studies exist examining the role of perceptions about campus authority figures in bystander intervention to address campus sexual violence. Nevertheless, findings from related lines of research seem to support the theory that beliefs about the normative attitudes and behaviors of campus administration (and other authority figures) may influence students' bystander intervention behaviors.

Several studies have established a connection between younger students' (i.e. in primary and secondary school) bystander intervention behavior related to bullying, and the normative behavior of school authority figures. For example, one study by Hektner and Swenson (2012) sampled elementary and high school students and their teachers, and found that teachers' self-reported actions and beliefs regarding bullying predicted students' self-reported sense of obligation to stop instances of bullying that they may witness. Specifically, the self-reported intervention behaviors of teachers who witnessed bullying among students was significantly positively related to their students' selfreported inclination toward bystander intervention. At the same time, teachers' beliefs that victims of bullying should do more to "assert themselves" was significantly negatively related to students' bystander intervention inclination (Hektner \& Swenson, 2012). 
Another study by McLaughlin, Arnold, and Boyd (2005), found that elementary school students who stated that they would report bullying to teachers did so because they believed teachers "could deal with the bullying more effectively [than a student], including sorting out the problem that caused the incident" (p. 20). A more recent qualitative study by Storer, Casey and Herrenkohl (2017) employed semi-structured focus groups with high schoolers to discuss what barriers they faced when it came to taking action as bystanders to help victims of bullying or dating violence witnessed at school. One of the major factors that they identified as inhibiting to prosocial bystander behavior was the perception that school officials would respond ineffectively to the situation, if they were either to witness it or be informed of it. The researchers concluded that "school personnel can facilitate both students' reporting of sensitive issues and their utilization of bystander behaviors by modeling proactive responses and facilitating positive student/teacher relationships" (Storer et al., 2017, p. 93).

In another related vein of research, Sulkowski (2011) investigated factors that influence college students' willingness to report threats of violence made by their peers. He found a significant positive association between students' willingness to report threats and their trust in the ability of campus authorities (i.e. administrators and security personnel) to handle crisis situations. Furthermore, Sulkowski found a significant relationship between students' feelings of "connectedness" with their campus community, and their willingness to report threats. This sense of campus-connectedness is conceptually similar to students' sense of campus community, which is discussed further in the following sub-section. 
Currently, the bystander intervention literature reflects a very nominal understanding of the role of campus administration in determining college students' behavior to prevent sexual violence. Based on the studies sampled above, however, it is reasonable to expect that students' bystander behavior may be related to their perceptions of how campus administration would act in response to campus sexual violence.

\section{Sense of Community}

One additional factor that has been suggested as important for determining college students' bystander intervention behavior is their sense of campus community (McMahon, 2015). "Sense of community" was conceptualized by Seymour Sarason (1974) as a fundamental feeling of belonging to, and contributing to, a social collective. A sense of community is, in part, the idea that one's network provides support and security to its members (Sarason, 1974). As McMillan and Chavis (1986, p. 9) later wrote, sense of community involves a "shared faith that members needs will be met through their commitment to be together." A community can be any group or groups of individuals with something in common, and a person can belong to multiple communities simultaneously (Nelson \& Prilleltensky, 2005). Colleges and universities have long been regarded as communities. In fact, "the university" was used as an exemplar community by McMillan and Chavis (1986) when they proposed their very well-regarded definition for sense of community, consisting of four main elements.

McMillan and Chavis (1986) described sense of community as a combination of the following elements: (1) membership, (2) influence, (3) integration and fulfillment of needs, and (4) shared emotional connection. Membership is related to feeling personally invested in and willing to sacrifice for the group (McMillan \& Chavis, 1986). For 
example, a student considering performing a bystander intervention behavior might be more willing to risk feeling uncomfortable, embarrassed, or even endangered if they believe their actions will benefit a group (or a member of a group) with whom they share a strong affiliation. In this way, membership might help students overcome audience inhibition and the failure to act barrier associated with Latané and Darley's (1970) fifth bystander step. On the other hand, membership inherently entails boundaries designating who belongs and who does not. This means it is possible that even a bystander with a strong sense of community might fail to take responsibility for intervening to help a noncommunity member. However, if helping non-members and members alike is in keeping with the community's standards of behavior, a strong sense of community may promote inter-group helping. In this case, helping others may be seen as simultaneously benefiting the group by upholding its desired reputation.

The sense of community element, influence, is a bidirectional concept relating to the influence that members have on one another and on the group as a whole, as well as the influence the group has on individuals (McMillan \& Chavis, 1986). A student who feels they have influence on their campus community might be more likely to attempt an intervention if they witness concerning behavior by another student, particularly if that person is doing something that is damaging to another group member or to the larger community. At the same time, the behavioral norms set by the community can influence an individual's inclination to either intervene or remain passive, as discussed in relation to social norms theory, TRA, and TPB. A greater sense of community may therefore correspond with a greater motivation to comply with the perceived norms of that community (Lapinski \& Rimal, 2005). However, this may only be the case when norms 
are seen as widely shared among community members. Students who feel highly connected to their campus in a broad sense might be influenced to go against the norms of a particular sub-community group when doing so would benefit the larger community.

Integration and fulfillment of needs is thought to be supported by shared values among community members, and shared emotional connection is reinforced through shared history, quality time, and experiencing important events together (McMillan \& Chavis, 1986). These two elements could be thought of as cumulative in some ways, wherein they contribute more to a person's sense of community over time. However, in a college setting, some evidence suggests that lowerclassmen are actually higher in sense of community than upperclassmen (Lounsbury \& DeNeui, 1996). As suggested above (see Peer Norms), lowerclassmen may rely more on their campus community to meet their needs, may be more likely to attend campus events and take part in activities, and may spend more time on campus and with other students do to dormlife - all of which might contribute to a greater sense of community. Upperclassmen, on the other hand, might begin to disengage from their campus communities and prioritize their off-campus connections as they look toward their future professions and/or family-lives (Lounsbury \& DeNeui, 1996). On- or off-campus living situation, as well as college or university size, are also thought to affect students' sense of campus community. Past research by Lounsbury and DeNeui (1996) revealed that students who lived on-campus, and those at smaller colleges (with fewer than 10,000 students), tended to have a greater sense of community compared to those living off-campus and those enrolled at larger colleges. A limited number of studies explore the connection between college students' sense of community and their bystander behavior to prevent sexual violence (McMahon, 2015). 
One example is a 2008 investigation by Banyard, which revealed a significant association between college students' sense of community and their professed willingness to intervene in a variety of hypothetical situations related to sexual violence. An earlier study by Banyard, Plante, and Moynihan (2004) found a similar correlation between sense of community and self-reports of actual bystander intervention behaviors. More recently, Bennett, Banyard, and Garnhart (2014) found a significant relation between sense of community and college students' actual behaviors aimed at helping friends, but not strangers. The reason for this distinction may be related to the boundaries of community membership discussed above, and the fact that friends are more likely than strangers to be seen as in-group members. That is to say, a higher sense of community may increase helping behaviors that benefit members of one's own group, but not necessarily increase intergroup helping. Alternatively, it's possible that students with greater sense of community may spend more time with their friends compared to students with lower sense of community, and therefore might encounter more opportunities to engage in bystander behaviors to help those friends.

A larger body of empirical evidence points to the important role of sense of community in determining bystander helping in contexts other than campus sexual violence prevention. As mentioned above, Sulkowski (2011) identified an association between college students' sense of connection with their campus community and their willingness to report violent threats made by peers. Additionally, using a non-collegiatebased sample of young adults from rural communities, Edwards, Mattingly, Dixon and Banyard (2014) found that perception of community efficacy was positively associated with bystander behavior to help friends experiencing intimate partner violence. From an 
even broader viewpoint, studies in the criminal justice literature have demonstrated a link between bystander intervention to stop neighborhood crime and a number of factors conceptually similar to sense of community, including social cohesion, collective efficacy, and social and emotional connection to neighbors (see McMahon, 2015, and Groff, 2015 for reviews).

There is abundant theoretical justification, and ample evidence from parallel fields that suggests an important role of sense of community in bystander intervention. Nevertheless, a paucity of research specifically examines sense of community as it relates to bystander intervention to address campus sexual violence. Additionally, as posited above, sense of community may affect the extent to which individuals are motivated to either comply with — or go against— - the norms espoused by different referent groups. However, no research currently exists exploring the potential moderating effect of sense of community on the normative influence of individuals' referent groups (i.e. for the current study, peers and campus administration).

\section{Literature Critique Summary}

As the theories and research outlined above indicate, peer norms, campus administrations, and sense of campus community are factors that evidence influencing college students' bystander intervention to prevent sexual violence. However, a number of gaps are apparent in the literature surrounding these concepts. First, peer norms, although fairly well researched in connection to bystander intervention intention or willingness, has rarely been studied in connection to actual self-reported intervention behaviors. Those studies that have investigated bystander behavior have reported mixed results (e.g., Brown et al., 2014). Additionally, the large majority of peer norms research 
has focused only on male samples. Second, perceived campus administrative response to sexual violence might serve as another normative reference affecting students' bystander behaviors to prevent sexual violence, but this avenue of research is yet to be empirically explored. Third, a very limited number of studies have investigated the influence of sense of community on bystander intervention behaviors. Fourth and finally, sense of community may play an important moderating role in determining the degree of influence that perceptions about peer norms and campus administration have on college students' bystander behavior, but no studies to date have investigated these potential interactions.

The bystander intervention approach is in many ways representative of great strides made in the field of campus sexual violence prevention. Nevertheless, more research is critically needed to inform the ongoing development of this relatively new approach. The current study represents an important step toward addressing some of the key gaps in the literature. 


\section{The Current Study}

Sexual violence is a serious and widespread problem for colleges and universities, and one which bystander intervention has the potential to reduce. However, as the theories and research outlined above suggest, there is a need to better understand the association between several understudied social and community factors and bystander behaviors by college students. The current study represents a crucial step toward building a stronger evidence base around bystander intervention to prevent campus sexual violence. The following section provides a detailed description of the specific aims and hypotheses of this investigation.

\section{Study Purpose, Research Questions, and Hypotheses}

The purpose of the present study is to contribute to the current knowledge base regarding the associations between bystander intervention behavior to prevent campus sexual violence and the key variables of peer norms, perceptions of campus administration, and sense of campus community. Findings from this study have the potential to inform the ongoing development and improvement of campus-based bystander intervention training programs. To that end, this investigation examined the main effects of perceived peer norms supportive of sexual violence, perceived campus administrative response to sexual violence, and sense of campus community on bystander behavior. Additionally, it tested sense of campus community as a moderator of the relationships between peer norms and bystander intervention behavior, as well as perceptions of campus administration and bystander intervention behavior.

Specifically, the current study addressed the following research questions and related hypotheses. 
Research Question 1: How are the following sources of social influence related to college students' self-reported bystander intervention behaviors?

a. Perceptions of peer norms supportive of sexual violence

b. Perceptions of campus administrative response to reported sexual violence

An abundance of theory (e.g., social norms, TPB, TRA) suggests a relation between peer norms and bystander intervention. In the realm of bystander intervention to prevent campus sexual violence, research supports this connection as well (e.g., Stein, 2007; Fabiano et al., 2003), although findings that are inconsistent with this connection have also emerged (Banyard \& Moynihan, 2011; Brown et al., 2014). The current study will reexamine the association between peer norms supportive of sexual violence and bystander intervention behavior. In addition to peers, campus authority figures have been suggested as having a possible normative influence on students' bystander behavior (McMahon, 2015). However, no research to date has examined the relationship between these factors. Thus, the following two hypotheses were tested.

Hypothesis 1: Perceived peer norms supportive of sexual violence will be related to bystander intervention behavior, such that higher perceptions of peer norms supportive of sexual violence will be associated with fewer bystander intervention behaviors.

Hypothesis 2: Perceptions of campus administrative response to sexual violence will be positively related to bystander intervention behavior, such that higher expected campus administrative responsiveness will be associated with more bystander intervention behaviors. 
Research Question 2: What is the role of sense of campus community in directly predicting college students' self-reported bystander intervention behavior?

The association between sense of community and helping behaviors has been established in the broader literature on neighborhood cohesion and social control of crime (for reviews, see Groff, 2015; and McMahon, 2014). There is some preliminary evidence for the relation between sense of community and bystander intervention to address campus sexual violence (e.g., Banyard, 2008; Bennet et. al., 2014), but very few studies have empirically examined this association. The proposed study seeks to add support to the role of sense of community in college students' bystander intervention behaviors. The following hypothesis will be tested.

Hypothesis 3: Sense of campus community will be positively related to bystander intervention behavior, such that increased sense of community will be associated with more bystander intervention behaviors.

Research Question 3: Do individuals' sense of campus community moderate the relationship between the following variables and bystander intervention behavior?

a. Perceptions of peer norms supportive of sexual violence

b. Perceptions of campus administrative response to sexual violence

The norms of referent groups (i.e., peers and campus administration) are thought to influence behavior to the extent that individuals are motivated to comply with those groups. Students with a stronger sense of campus community may feel more motivation to act in compliance with the norms of campus sub-groups that promote behaviors which benefit the larger campus community. Likewise, a high sense of campus community may 
weaken the behavioral influence of group norms that promote behavior that could harm the campus community. While no empirical studies have tested these assumptions, a moderating effect of sense of community could explain Banyard and Moynihan's (2011) unexpected finding that peer norms supportive of sexual violence were associated with more bystander intervention behaviors for freshmen students (who may have a greater sense of campus community than upperclassmen for various reasons discussed above). The current study will examine the possible moderating role of sense of campus community on the association between both peer norms and bystander behavior, and campus administrative responsiveness and bystander behavior. The final two hypotheses will therefore be tested.

Hypothesis 4: The association between bystander intervention behavior and peer norms supportive of sexual violence will be moderated by sense of campus community, such that the impact of peer norms supportive of sexual violence on bystander intervention behavior will become less negative (and may even become positive) as sense of community increases.

Hypothesis 5: The association between bystander intervention behavior and perceptions of campus administrative response to sexual violence will be moderated by sense of campus community, such that the positive impact of perceptions of campus administrative responsiveness on bystander intervention behavior will increase as sense of community increases. 


\section{Methods}

\section{Participants}

This study used data collected from undergraduate and graduate students at Portland State University who participated in an online campus climate survey in the spring of 2016. Students who were under the age of 18 , and those who were enrolled in the university's Intensive English Language Program were not invited to participate in the PSU campus climate survey. The survey used a random sampling methodology, and invited $n=12,556$ students to participate. A $19 \%$ response rate was obtained, resulting in $\mathrm{n}=2370$ participants. According to the Campus Climate Report (Portland State University, 2016), there was some gender bias in who chose to participate in the survey, in that $21 \%$ of female students who were asked to take the survey responded to it versus $14 \%$ of male students. 2

\section{Demographic Variables}

Participants were predominantly White (63.8\%; Asian, 10\%; Multiracial, 9.7\%; Latino/a, 7.9\%; Black, 2.4\%). The majority identified as women (73.8\%; men, 21.5\%; other/non-binary, $3.9 \% ; .8 \%$ preferred not to disclose). The average participant's age was $27(\mathrm{SD}=8.89$ years $)$. Other demographic variables relevant to the current investigation include living situation (87.4\% reported living off-campus), and year in school (Undergraduate: $10.3 \%$ first year; $10.5 \%$ second year; $21.7 \%$ third year; $18.1 \%$ fourth year; $15.1 \%$ fifth year or higher; Graduate, $23.3 \%$ ).

\section{Measures}

\footnotetext{
${ }^{2}$ For the Campus Climate Report, gender was classified based on students' institutional records. For the current study, reported demographics and all analyses involving gender as a variable relied on participants' own responses to the gender-identity question in the survey.
} 
The survey measures were predominantly those developed by the Administrator Research Campus Climate Collaborative (ARC3), a research collaborative made up of sexual assault researchers and student affairs professionals (n.d.). The goal of ARC3 was to develop, and make freely available, a tool for campuses to use to assess perpetration and victimization of sexual misconduct among students. The full survey was pre-tested by ARC3 in 2015 with over 2,200 students from four universities across the country. Within a year of it going online, over 300 institutions had requested to use the ARC3 survey on their campuses (New, 2016).

Some changes were made to the original ARC3 survey wording in order to tailor the measures to Portland State University's campus and student population. See Appendix A for a complete listing of the current study's measures, which are described below.

Bystander Intervention Behavior. Seven items were used to measure participants' bystander intervention behavior. These items were based on work by Banyard (2008), and adapted by ARC3. Participants read the following prompt: Think about how many times you have done any of the following behaviors since you enrolled at PSU. An example item read: Tried to distract someone who was taking a drunk person to another room or trying to get them to do something sexual. Possible responses ranged from 1 (Never) to 5 (Always); an additional N/A response was used to indicate that the situation never arose. Excellent reliability of this scale was observed in this sample, with a Cronbach's alpha of .94. This scale was analyzed based on its total score, as an average of all items with numeric responses. 
Items with N/A responses were not included in the calculation of participants' average scores. However, to better understand the variation in students' opportunities to intervene, a sum total of N/A responses was calculated for each participant. An exploratory analysis which analyzed number of N/A responses as an outcome variable was conducted in order to to shed light on variables related to bystander opportunity. These results are presented following the description of findings related to the hypothesis testing.

Peer Norms. The peer norms scale for the current study is a subset of those developed by ARC3 and included on Portland State's climate survey. This scale was adapted from the work of DeKeseredy and Kelly (1995), and measures perceived peer norms related to the acceptance of sexual assault, as well other forms of sexual, emotional, and physical dating violence. A six-item subscale focused on sexual violence was used (items reflecting physical and emotional violence not clearly linked to sexual violence were dropped). Each item used in the current study asked participants to judge how likely their friends would be to approve of a behavior related to sexual violence. An example item is: My friends would approve of getting someone drunk or high in order to have sex with them. Participants responded to each statement using a five-point scale ranging from 1 (Strongly Disagree) to 5 (Strongly Agree). Good reliability was observed, with a Cronbach's alpha of .83 . This scale was analyzed based on its total score, as a centered average of the six items.

Campus Administrative Response. This measure consisted of five items developed by the ARC3 researchers to assess perceptions of college/university administrative responsiveness to reports of sexual misconduct. The item on this scale 
assessed participants' perceptions of how likely the administration would be to take a report of sexual misconduct seriously, conduct a fair investigation, take actions against an offender, and address factors that contribute to sexual misconduct on campus. A sample item is: How likely is it that PSU administrators would take the report seriously? Responses were collected on a five-point scale, ranging from 1 (Not at All) to 5 (Extremely). Good internal reliability of this scale was observed, with Cronbach's alpha equal to 93 . This scale was analyzed based on its total score, as a centered average of the five items.

Sense of Campus Community. The Brief Sense of Community Scale (BSCS; Peterson, Speer \& McMillan, 2008) was adapted and used to assess participants' sense of community specific to the Portland State University campus. This measure was not included in ARC3's survey tool, but has appeared in a number of other campus climate tools (e.g., the iSpeak survey developed by researchers at Rutgers University; McMahon, Stepleton \& Cusano, 2016). Minor adaptations were made to the original measurement prompt and items in order to hone in on the campus-specific community (for example, a BSCS item originally reading I can get what I need in this community was changed to I can get what I need in this campus community). Written instructions asked participants to think about their Portland State campus community, and then prompted them to report their level of agreement with eight statements, an example being: I feel like a member of this campus community. The five possible responses to each item ranged from 1 (Strongly Disagree) to 5 (Strongly Agree). Good scale reliability was observed in this sample, with Cronbach's alpha calculated as .91 . This scale was analyzed based on its total score, as a 
centered average of the eight items, with higher scores indicating greater sense of campus community.

\section{Study Design and Procedure}

The current study used a cross-sectional design to analyze data previously collected through survey methods for a campus-wide Climate Assessment. The larger survey protocol included the measures outlined above and analyzed in the current study, as well as measures of sexual victimization experiences, sexual perpetration behaviors, campus resource knowledge, conceptualization of sexual consent, and participation in campus groups and activities. The 12,556 students who were chosen via random sampling methods were contacted using the university email system with an invitation to participate in the Campus Climate Assessment. Students were emailed up to six times, the first time with a cover letter from their University President. In each email correspondence, reference was made to monetary incentives in the form of a raffle drawing for Amazon gift cards ranging in values from $\$ 25$ to $\$ 300$. Participants provided their informed consent in an online format prior to completing the online survey. A list of campus and community support resources was prominently displayed on every page of the survey to ensure that students in need of services could access them. The current study was reviewed by Portland State University's Office of Research Integrity, who determined that IRB approval was not required. All of the data preparation and analyses for this study were conducted using SPSS Version 24 (IBM Corporation, 2016).

Data Preparation. Participants' mean scores were calculated for the scales measuring bystander intervention, peer norms, campus administrative response, and sense of campus community in order to produce composite scores for each assessment device. 
The number of times each participant chose $N / A$ in response to the bystander intervention items was computed into a new variable. Means and descriptive statistics for each of these variables are presented in Table 1.

The three main predictor measures (peer norms, campus administrative response, and sense of community) were each centered on their overall means. Centering these variables allowed for more interpretable regression results, and model intercepts that represented the expected outcome for participants with average scores on the predictors. Two interaction terms were computed: 1) peer norms by sense of community; and 2) campus administrative response by sense of community. Additionally, dummy codes were created for gender (two dummy variables: one for male; and one for nonbinary/undisclosed gender, with female as the reference category for both), and year in school (five dummy variables with freshmen in their first year of school as the reference category for each other year in school option). 


\section{Results}

This section begins by outlining the patterns of missing-ness found in the data. Next, details of the exclusion criteria for this study are discussed, including participants who were missing more than $40 \%$ of the items on any given scale, and those who failed the attention check. Then, the process used to decide on control variables is explained. Following this, the results of the main regression analyses used to address the five hypotheses are presented. Finally, results from an exploratory analysis that examined factors associated with the use of the N/A response on the bystander intervention scale are described.

\section{Preliminary Analyses}

Missing data. Of the 2370 participants who began the Campus Climate survey, $223(9.4 \%)$ dropped out before answering a single item on any of the study scales.

Respondents who were missing more than $40 \%$ of the items for any particular scale were excluded from the calculation of scale average scores, and ultimately excluded from the analyses involving those scales. For the bystander intervention scale, 284 participants (or $12 \%$ of the total) responded to fewer than 5 items, and were therefore excluded from the analyses. On the peer norms scale, 262 participants (11.1\%) responded to fewer than 4 items. Participants who answered fewer than five sense of community items amounted to $302(12.7 \%)$ individuals. Finally, $324(13.7 \%)$ participants provided responses to fewer than 3 perceived administrative response scale-items. As these observations indicate, in the vast majority of cases, participants who were missing data on the bystander intervention behaviors scale were missing data on the other scales, as well. 
A series of chi-square tests were used to assess whether data missing for each scale was related to participant gender and/or year in school (i.e., first year undergraduate, second year undergraduate, etc.). Results indicates that gender was significantly related to missing bystander intervention responses, $\chi^{2}(2)=6.87, p=.032$, with $14 \%$ of male participants missing more than 2 scale items compared to $11.4 \%$ of women and $7.4 \%$ of students with a non-binary or an undisclosed gender. Likewise, gender was significantly related to missing more than 3 peer norms items, $\chi^{2}(2)=69.72$, $p=.008$, with patterns again showing that men had more missing data than women, and non-binary or undisclosed gendered students had the least amount of missing data $(14.7 \%, 10.2 \%$, and $7.4 \%$ respectively). Gender was not significantly related to missing more than 2 items on the perceptions of administrative response scale, $\chi^{2}(2)=3.60, p=$ .165 , or to missing more than 3 items on the sense of campus community scale, $\chi^{2}(2)=$ $5.28, p=.071$, although the pattern of missing-ness remained the same in both cases, with men missing the most followed by women and other/undisclosed gendered students. The issue of data missing not at random and the potential for biased results is discussed later, in the limitations section. Participants did not differ in how likely they were to have missing data exceeding the exclusion threshold on any of the scales based on their year in school.

Failed attention checks. In addition to participants with missing data that exceeded the $40 \%$ threshold for each scale, participants were excluded from the analysis if they failed $(n=72)$, or did not answer $(n=285)$ the attention check embedded in the bystander intervention scale. 
Control Variables. Past research suggests that both gender and year in school may be important variables to control for, as these factors may relate to college students' sexual violence bystander intervention behaviors (e.g., Banyard \& Moynihan, 2011). Living situation also may affect bystander behavior, as students who live on or near campus may spend more time together and share a closer relationship with one another, which may lead to more bystander intervention behavior.

To test the importance of including any of these covariates, a series of regression analyses were conducted. Results confirmed that gender was significantly related to bystander intervention. On average, males had bystander intervention behavior scores that were .40 points lower compared to females $(b=-.399, S E=.077, \beta=.123, p<.01)$, and non-binary/undisclosed gendered students had bystander scores that were .40 points higher than females $(b=.401, S E=.145, \beta=.066, p<.01)$. Additionally, living situation was found to be significantly associated with bystander behavior, in that students living on or within a half mile of campus had significantly higher bystander intervention scores $(b=.238, S E=.072, \beta=.079, p<.01)$ as compared to students living more than a half a mile off campus. No significant association was found between year in school and bystander intervention. Subsequently, only gender and living situation were controlled for in the main regression analyses for this study. A summary of the significant findings from the preliminary analyses of control variables are presented in Table 2 .

\section{Inferential Analyses}

Ordinary least squares hierarchical regressions were used to test the proposed study hypotheses. Only the dummy-coded covariates (gender and living situation) were entered into the first step, and thus controlled for in all subsequent steps. 
Research Questions 1 \& 2. A two-step regression approach was used to address research questions 1 and 2, which proposed that there would be significant direct associations between bystander intervention behavior and peer norms (hypothesis 1), perceived administrative response (hypothesis 2), and sense of community (hypothesis 3). All three predictors were entered into the second step of the regression model. Results are described below, and presented in Table 3.

Hypothesis 1. Results indicated support for the hypothesis that peer norms are significantly related to bystander intervention, in that peer norms more supportive of sexual violence were found to be associated with lower bystander intervention scores $(b$ $=-.361, S E=.086, \beta=-.102, p<.01)$, while controlling for gender, living situation, and the other main predictors. For every one point increase in participants' scores for peer norms supportive of sexual violence, there was an expected decrease in bystander intervention behavior scores of approximately .36 points.

This result should be interpreted cautiously, in part due to the very small associated effect size $\left(r^{2}=.011\right)$. Additionally, when checking for assumptions violations, heteroscedasticity was observed in the scatterplots of the standardized residuals. This is a problem that could bias the error estimates and therefore the significance tests, but not the estimates of the coefficients. Heteroscedasticity may have impacted the findings of all of the analyses presented below, and is discussed again in the limitations section.

Hypothesis 2. The hypothesis that perceptions of campus administrative response to sexual violence would be positively related to bystander intervention behavior by students was rejected. However, an unanticipated negative association was uncovered. 
Results indicated that as perceptions of campus administrative responsiveness increased, bystander intervention behaviors tended to decrease $(b=-.122, S E=.036, \beta=-.091, p<$ .01). For each point increase in perceptions of campus administrative responsiveness to sexual violence, a .12 point decrease in bystander intervention could be expected. This finding also had a very small effect size $\left(r^{2}=.007\right)$.

Hypothesis 3 . The hypothesis that sense of campus community would be positively associated with bystander intervention behavior was not supported. Controlling for the other variables in the model, no significant effect of sense of campus community was found $(b=.056, S E=.046, \beta=.033, p=.225)$.

Research Question 3. This research question inquired as to whether there may be a moderating effect of sense of campus community on the relationship between bystander intervention and the two predictors, perceived peer norms supportive of sexual violence (hypothesis 4), and perceived campus administrative response to sexual violence (hypothesis 5). To address this line of inquiry, two regression models were tested (i.e., one for each of the associated hypotheses), each building off of the hierarchical model described above. As the results of research question two indicate, sense of campus community was not found to be a significant predictor of bystander intervention. Nevertheless, it was decided that value remained in exploring this variable as a potential moderator. The hypothesized interactions with sense of campus community have never been previously investigated, and therefore even non-significant trends may provide some insights and inform future research directions. The results of these analyses are discussed below, and presented in Table 4 and Table 5. 
Hypothesis 4. It was expected that sense of campus community would interact with the effect of peer norms by reducing the negative effect of peer norms supportive of sexual violence on college students' bystander intervention behavior. Support was not found for this hypothesis, as the coefficient for the interaction term was found to be nonsignificant $(b=-.110, S E=.084, \beta=-.032, p=.189)$. For exploratory purposes, simple slopes of the association between peer norms and bystander intervention were plotted for low (-1 SD below the mean), and high (+1 SD above the mean) values of sense of community. A graph of these slopes is presented in Figure 1, and show the negative association between bystander intervention and peer norms supportive of sexual violence increases, as well as the slight (non-significant) difference in slopes predicted for high versus low sense of community.

Hypothesis 5. It was hypothesized that sense of campus community would moderate the relationship between perceived campus administrative response to sexual violence and bystander intervention. Findings did not support this hypothesis $(b=.036$, $S E=.035, \beta=.025, p=.315)$. Simple slopes of the association between perceptions of administrative response and bystander intervention were again plotted for low (-1 SD below the mean), and high (+1 SD above the mean) sense of campus community, and are presented in Figure 2. This graph shows the negative association between perceived campus administrative responsiveness and bystander intervention behavior, as well as the slight (n.s.) difference in slopes expected for participants with lower versus higher sense of campus community.

\section{Exploratory Analyses}


The option of responding to items on the bystander intervention scale with an N/A was provided to participants and is an attempt to control for the potential confounding of bystander behavior and bystander opportunity. In other words, students who had not been in any situations where they had the opportunity to act in the ways described on the bystander intervention scale items could select $N / A$, rather than Never, resulting in bystander intervention scores that are not artificially reduced by a lack of opportunity to engage in bystander behavior. This allowed for the main analyses, described above, to use a measure of bystander behavior that, in theory, related to how often students who have the opportunity to intervene actually do so. Another important line of inquiry that was not captured in the above analyses relates to the question of: who is most likely to have opportunities to intervene? To examine differences in bystander opportunity, a regression analysis was run, this time with number of N/A responses as the outcome variable. In addition to the predictors and controls used in the main analyses, bystander intervention scores (used as the outcome variable in the analyses described above) were mean-centered and entered as a predictor variable.

Findings revealed that living less than a half mile off campus, perceptions of peer norms supportive of sexual violence, as well as bystander intervention scores, were all significantly related to number of $N / A$ responses. Students who lived within a half mile of campus had fewer N/A responses compared to those that lived a half mile or more off campus $(b=-.352, S E=.123, \beta=-.068, p<.01)$. Peer norms more supportive of sexual violence were also associated with fewer $N / A$ responses $(b=-.640, S E=.144, \beta=-.106$, $p<.01)$. Bystander intervention behavior was positively associated with N/A responses, in that participants with higher bystander intervention scores also tended to use the $N / A$ 
response option more often $(b=.450, S E=.041, \beta=.263, p<.01)$. A summary of these results appears in Table 6. 


\section{Discussion}

The current study has important implications for the field of bystander intervention to prevent sexual violence, in terms of research as well as practice. As campuses continue to look for ways to improve their sexual violence prevention efforts, the results of the current study reflect McMahon's (2015) recommendation that factors beyond the individual be given more attention. While individual skills and knowledge remain essential for overcoming bystander barriers, aspects of the campus environment may be strongly related to bystander behavior as well (Banyard, 2011). Although the measures used in the current study were collected at the individual-level of analysis, they may still offer informative insights about how (perceived) social factors support or inhibit prosocial bystander intervention by college students.

The findings from the current investigation are discussed below with regard to their implications for campus prevention efforts, as well as future research directions. Study limitations are also described toward the end of this section.

\section{Peer Norms Supportive of Sexual Violence}

Findings from this study support the hypothesis that peer support for sexual violence is negatively associated with college students' bystander intervention behaviors. This result aligns with some of the findings from previous investigations of college men's perceptions of their peers' norms. For example, past research has found associations between peer approval of sexual aggression and lower prosocial bystander intervention attitudes (Orchowski et al., 2016), as well as less willingness to intervene (Brown and Messman-Moore, 2010). The current study extends this research by using a behavioral measure of bystander intervention. Additionally, by using a mixed-gendered sample, this 
study lends support to the idea that the association between perceptions of peer norms supportive of sexual violence and bystander intervention extends to female college students, who are understudied in terms of this type of normative influence.

However, the variance in bystander intervention behaviors that was explained by an association with peer norms supportive of sexual violence was very small for the current sample, despite the significant finding. The reason for this may be that the sample used was quite large, meaning that there was enough power to detect even very minimal effects. Additionally, the overall sample mean for peer norms supportive of sexual violence was found to be very low. In fact, although individual scores spanned the entire possible range of the scale, the majority of the students sampled indicated that they strongly disagreed that their peers would approve of any of the actions described in the scale items. Therefore, large-scale initiatives to improve norms related to perceived peer support for sexual violence may not be an efficient use of campus resources, at least for students who are represented by the current study's sample. Instead, a more effective approach may be to first attempt to identify campus sub-populations (or even individual students) for whom perceived peer norms supportive of sexual violence may tend to be higher than average, and target interventions aimed at changing their norms. It is possible that data from the larger Campus Climate survey could be used to help identifying subpopulations with problematic perceptions of norms. For instance, by examining associations between peer norms scores and participants' responses to questions about involvement (or lack there-of) in campus clubs, athletics, or other activities it may be possible to craft interventions that expose these individuals to groups of student with 
more positive norms, which in turn may influence their thinking about the acceptance of violent norms.

At the same time, it is important to consider that impression management by participants could have impacted their responses to this scale. If that was the case, the calculated peer norms scores might be lower than they would have been if impression management were not a factor. Additionally, as mentioned previously, men both declined to participate in the study and provided incomplete data at a higher rate than women. The issues of volunteer- and non-response bias (which in the current study are both tied to gender) are discussed further in the limitations section.

\section{Perceptions of Campus Response to Sexual Violence}

A positive association between students' perceptions of the campus administration as responsive to sexual violence and students' self-reported bystander behaviors was expected. This hypothesis was not supported by the data; however, the results were nonetheless interesting. Instead of a positive association, a negative association was observed. This means that students' who perceived the campus as less responsive to sexual violence (i.e., less supportive of survivors, less supportive of those filing reports, less likely to work to prevent sexual violence, etc.) tended to have intervened more as active bystanders than other students, and as participants' perceptions of administrative responsiveness increased their bystander behavior scores tended to decrease. There are several possible ways to interpret this unexpected negative association, two of which are discussed below.

First, it might be the case that students who are more aware of the problem of campus sexual violence are both more likely to actively engage in its prevention by 
intervening in the situations described in the bystander intervention scale items, and are more likely to have higher expectations about how campus administration should respond to sexual misconduct. In other words, students who intervene to help others may themselves be harsher critics of the administration's efforts to handle sexual violence. A second possibility is that students who perceive the campus administration as more responsive to sexual violence may be less likely to intervene in the ways measured by the bystander scale. However, this does not rule out the possibility that students with high perceptions of administrative responsiveness intervene in ways that are not captured in the bystander intervention scale. For instance, they may be more likely to intervene by calling campus security or by filing a formal report or complaint against another student. This may be the case since those students may have more confidence in the ability of campus authorities to effectively handle such situations. Some past research findings in the broader campus safety literature support this explanation. For example, Sulkowski's (2011) finding that students with greater trust in campus authorities stated that they would be more willing to make reports against peers who had threatened to commit violence.

These two interpretations are not mutually exclusive, but are meant to offer different possible ways of understanding this pattern of results. Further investigation is necessary before any implications can be drawn about the actual nature of the relationship suggested by these findings.

As with peer norms, the effect size observed for the correlation between bystander intervention and perceptions of campus administrative response was very small. However, this study marks the first empirical investigation into the relationship between 
these variables. Therefore, these results should be considered an initial indication that the association is one that warrants further investigation. Moreover, additional efforts directed toward measurement development around perceptions of campus authority could greatly improve the sensitivity of measurement offering the potential for future researchers to gain a better understanding of this phenomenon. For example, it may be that multiple factors contribute to students' overall perceptions of campus responsiveness, and longer scales that encompass a broader array of factors would do a better job of capturing the associated variation in bystander intervention behaviors. Factors suggested by related bodies of literature, which might combine to form students' perceptions of campus administrative responsiveness, include trust (Sulkowski, 2011), as well as behavioral and attitudinal modeling (Hektner \& Swenson, 2012; McMahon, 2015; Storer et al., 2017).

\section{The Role of Sense of Community}

A goal of this study was to shed light on the role of sense of campus community in bystander intervention. College students' sense of campus community was expected not only to directly relate to their bystander intervention behavior, but to also moderate the relationship between peer norms and bystander intervention as well as perceptions of campus administration and bystander intervention. However, none of the hypothesized associations with sense of campus community were supported by this study's findings.

Few studies have examined the role of sense of community in bystander behavior to address campus sexual violence. Although the current findings do not highlight a significant association, additional research is still needed. Future investigations can build upon this study by considering other ways that sense of community could be more 
productively explored. For instance, rather than asking participants to think about their broad campus community when answering sense of community items, it may be more informative to ask them to consider a more focused campus community in which they participate when competing this measure. Follow-up questions could also ask participants to identify the campus sub-community that they spend the most time with, which could allow researchers to perform group-level analyses of factors related to sense of campus community and bystander intervention behavior.

While the hypothesis that sense of community would be positively associated with helping behaviors is supported by some research findings (e.g., Banyard, 2008; Bennett et al., 2014), it has also been suggested that low sense of community may be an indicator of a student who is more critical of their circumstances. For example, low sense of community could result from an awareness of problems or injustices in one's community, which might also motivate individuals to act in ways that would create positive changes (Mannarini \& Fedi, 2009). Additionally, in the case of dangerous community environments, a low sense of community might act as a protective factor that can help community members cope by providing some distance (i.e., real and/or emotional) from negative people and situations (Brodsky, 1996). To apply these theories to the phenomenon in question, future research should investigate whether a low sense of community may be associated with more activism around sexual violence prevention. Future research should also explore whether a low sense of community could be intentionally sustained by some students if they are members of campus communities that have especially high rates of violence-including sexual violence.

\section{Bystander Opportunity}


Participants' frequency of use of N/A on the bystander intervention scale was analyzed as an outcome, with the intention of understanding more about what factors may be related to having the opportunity to intervene. An important but difficult distinction for bystander intervention researchers is the difference between participants' bystander behavior and the number of opportunities they had to intervene (McMahon, Palmer, Banyard, Murphy, \& Gidycz, 2017). The results suggested that compared to students who live farther off campus, students who live on or near campus may have more opportunities to intervene, at least in the ways captured by the bystander intervention scale. This finding may be useful for bystander program practitioners looking to target their programs at students with the greatest opportunity to intervene (according to the current sample, those living on-campus). One limitation of this scale is that it relates to a list of seven particular bystander actions, and may not capture some of the bystander behaviors related to sexual violence prevention actually engaged in by different groups of participants. Future research should explore whether off-campus students (and other groups of students with lower than average intervention scores) are more likely to engage in different kinds of bystander intervention behaviors around sexual violence, compared to on-campus students.

Fewer N/A responses were also observed among students with peer norms more supportive of sexual violence. This finding indicates that peer norms supportive of sexual violence may not obscure students' ability to identify situations as intervention appropriate. It also supports the notion that bystander intervention programs may be highly effective if they are able to target campus groups with problematic peer norms. This possibility is in line with previous conclusions drawn by Banyard and Moynihan 
(2011), who uncovered an unexpected positive relation between peer norms more supportive of sexual violence and bystander intervention behavior. However, the use of $N / A$ versus Never may have been a confusing distinction for participants in the current study.

The prompt for the bystander intervention asks students to report on how often they performed a set of helping behaviors on a scale ranging from Never $=1$ to Always $=$ 5, with an additional $N / A$ option. While the $N / A$ response option is intended to be used by students who have never encountered the situation described in the item (e.g., they may not attend events where alcohol is served, so they have never been able to walk "a friend who has had too much to drink home"), some students that this would apply to may have mistakenly chosen Never for their response, due to confusion between the appropriate use of Never and N/A. Alternatively, there may be students who had opportunities to do the actions described by the scale items, but they failed to notice or failed to identify the situation as intervention appropriate. Those students may have chosen the N/A option when Never would be more appropriate.

\section{Limitations}

This study has several limitations which are worth noting. First to the uniqueness of this study's sample, findings may not be generalizable to all college students on all campuses. Portland State University is distinct in several ways, including its long record of enrolling veterans, the tendency for students to be older than traditional college students, and the fact that many students commute some distance between their homes and campus. Additionally, the ethnic make-up of Portland State's student body is fairly 
homogenous, as reflected in the demographics of the current study's sample. Future research should attempt to replicate this study with more diverse students and campuses.

Second, selection bias and non-response bias may have impacted the results of this study. As described above, women were more likely than men to participate in the campus climate survey, and were also more likely to provide complete data on the measures used in this study. One likely possibility is that students' experiences regarding campus sexual violence was related to patterns of missing data. For example, some of the campus climate survey questions asked participants if they had ever enacted various sexually violence behaviors. Since students who had committed those acts may have been reluctant to admit to them, even on an anonymous survey, perpetrators might have had particularly high rates of attrition. Other factors, too, could have contributed to patterns of attrition or missing data, such as students feeling triggered by certain questions about victimization, or students without personal experience with sexual violence feeling unmotivated to respond.

Third, the current study is cross-sectional in design, and as a result cannot infer causality in relations between the measured constructs. Future research should address this limitation by using research designs that allow for the observation of more certain causal effects. Longitudinal designs may be particularly useful in this regard. For example, a cross-lagged panel design could be used to assess whether reductions in peer norms supportive of sexual violence at the individual-level lead to increases in bystander intervention behavior over time.

Fourth, the results of this study should be interpreted with caution, as the data violated the regression analysis assumption of independent errors. Plots of the 
standardized predicted values with the standardized residuals showed a visible pattern, signaling that there was heteroscedasticity, or unequal error variance. Using a robust regression or a weighted least squares analysis method was considered, but was determined to be beyond the current scope of resources (including time and statistical knowledge) for this study. Although heteroscedasticity can result in standard error predictions that are biased, it does not affect the estimations of the coefficients. In other words, the intercepts and slopes are not biased by the assumption violation, but the standard errors may be underestimated, resulting in a greater chance of finding statistical significance. Because of the large sample size used in the current study, it is likely that even if robust techniques had been used, very small effects would still be found to be significant. For this reason, it is important to consider effect sizes when thinking about the practical significance of study findings, especially when samples are large.

Fifth and finally, the results that were found to be significant in the current study all had very small associated effect sizes, both in terms of the partial variance explained by each predictor and in terms of the full variance explained by each of the models tested (see $r^{2}$ and $R^{2}$ in Tables 2-5). In fact, the total variance in bystander intervention behavior scores explained by each of the full regression models was just $4.7 \%$ (see Table 4 and Table 5). The observation of very small effect sizes does not nullify the significance of the observed associations; however, it suggests that other factors not included in these analyses may be more strongly associated with college students' bystander intervention behavior. 


\section{Conclusion}

The problem of campus sexual violence is a pervasive and consequential one, but the bystander intervention approach offers a promising direction for its prevention (McMahon, 2015). Understanding more about how peer norms and perceptions of campus administrative responsiveness relate to bystander behavior to address sexual violence has important implications for the development of more effective campus prevention programs (Foubert et al., 2010). This study helps to address a number of critical gaps in the campus sexual violence bystander literature that have been identified by experts in the field (e.g., McMahon, 2015). The results of this investigation replicate and expand on prior research around the role of peer norms in bystander behavior. They also offer unique insight into the association between bystander intervention behavior and perceptions of campus administrative responsiveness to sexual violence, suggesting that additional factors and measurement considerations in this area warrant investigation. Although no association between sense of campus community and bystander intervention was found in this study, future research should continue to investigate the potential relationship from different angles. 
Table 1.

Descriptive Statistics

\begin{tabular}{llcc}
\hline Variable & $\mathrm{N}$ & Mean & Std. Deviation \\
\hline Bystander Intervention Behavior $^{\mathrm{a}}$ & & & 1.299 \\
Sense of Campus Community & 1753 & 2.659 & .762 \\
Perceived Peer Norms & 1997 & 3.206 & .379 \\
Perceived Admin. Response & 2009 & 1.165 & .971 \\
Number of N/A Responses $^{\mathrm{b}}$ & 1932 & 3.391 & 2.74 \\
Valid N (listwise) & 2013 & 2.287 &
\end{tabular}

Note: Values are for participants with no missing scale averages, and prior to centering predictors.

Outcome variables are superscripted $(\mathrm{a}, \mathrm{b})$ 
Table 2.

Control Variables: Relationship to Bystander Intervention Behavior

\begin{tabular}{|c|c|c|c|c|c|}
\hline \multirow[b]{2}{*}{ Gender $^{\mathrm{a}}$} & \multicolumn{2}{|c|}{$\begin{array}{l}\text { Unstandardized } \\
\text { Coefficients }\end{array}$} & \multirow{2}{*}{$\begin{array}{c}\begin{array}{c}\text { Standardized } \\
\text { Coefficients }\end{array} \\
\beta\end{array}$} & \multirow[b]{2}{*}{$t$} & \multirow[b]{2}{*}{ Sig } \\
\hline & $b$ & Std. Error & & & \\
\hline Women & 2.719 & .035 & & 76.762 & .000 \\
\hline Difference for Men & -.399 & .077 & -.123 & -5.151 & .000 \\
\hline $\begin{array}{l}\text { Difference for } \\
\text { other/undisclosed }\end{array}$ & .401 & .145 & .066 & 2.769 & .006 \\
\hline \multicolumn{6}{|l|}{ Living Situation $^{\mathrm{b}}$} \\
\hline Off Campus (>.5 mi) & 2.603 & .036 & & 72.707 & .000 \\
\hline Diff. for On Campus & .238 & .072 & .079 & 3.301 & .001 \\
\hline
\end{tabular}

Note: Separate analyses tested associations between the two controls (a and b) and the outcome 
Table 3.

Main effects of Predictors, controlling for Gender and Living Situation

\begin{tabular}{|c|c|c|c|c|}
\hline $\begin{array}{l}\text { Predictor } \\
\text { Model } 1\end{array}$ & $b$ & $\begin{array}{c}95 \% \mathrm{CI} \\
(\mathrm{LL}, \mathrm{UL})\end{array}$ & $\beta$ & $r^{2}$ \\
\hline (Intercept) & $2.681 *$ & $(2.60,2.76)$ & & \\
\hline Living On Campus & $.207 *$ & $(.06, .35)$ & .069 & .005 \\
\hline Gender Male & $-.406^{*}$ & $(-.56,-.25)$ & -.125 & .016 \\
\hline \multirow[t]{2}{*}{ Gender non-binary/undisclosed } & $.383^{*}$ & $\left(\begin{array}{ll}.09, & .68\end{array}\right)$ & .063 & .004 \\
\hline & & & & $R^{2}=.027 *$ \\
\hline \multicolumn{5}{|l|}{ Model 2} \\
\hline (Intercept) & $2.665^{*}$ & $(2.59,2.74)$ & & \\
\hline Living On Campus & $.207 *$ & $(.06, .35)$ & .069 & .005 \\
\hline Gender Male & $-.341 *$ & $(-.50,-.19)$ & -.105 & .011 \\
\hline Gender non-binary/undisclosed & $.345^{*}$ & $(.05, .64)$ & .057 & .003 \\
\hline Peer Norms & $-.361 *$ & $(-.53,-.19)$ & -.102 & .011 \\
\hline Perceived Admin. Res. & $-.122 *$ & $(-.19,-.05)$ & -.091 & .007 \\
\hline \multirow[t]{2}{*}{ Sense of Campus Community } & .056 & $(-.04, .15)$ & .033 & .001 \\
\hline & & & & $\begin{array}{r}R^{2}=.044 * \\
\Delta R^{2}=.017 *\end{array}$ \\
\hline
\end{tabular}

Note: Dependent variable is Bystander Intervention Behavior; $r^{2}$ is the partial correlation squared 
Table 4.

Moderating Effects of Sense of Campus Community (SOC) with Peer Norms

\begin{tabular}{|c|c|c|c|c|}
\hline Predictor & $b$ & $\begin{array}{c}95 \% \mathrm{CI} \\
(\mathrm{LL}, \mathrm{UL})\end{array}$ & $\beta$ & $r^{2}$ \\
\hline (Intercept) & $2.653 *$ & $(2.57,2.73)$ & & \\
\hline Living On Campus & $.192 *$ & $(.05, .33)$ & .063 & .004 \\
\hline Gender Male & $-.356^{*}$ & $(-.51,-.20)$ & -.110 & .012 \\
\hline Gender non-binary/undisclosed & $.387 *$ & $(.10, .68)$ & .063 & .004 \\
\hline Peer Norms & $-.415^{*}$ & $(-.57,-.26)$ & -.124 & .015 \\
\hline Perceived Admin. Resp. & $-.097 *$ & $(-.17,-.03)$ & -.073 & .004 \\
\hline SOC & .057 & $(-.03, .15)$ & .033 & .001 \\
\hline \multirow[t]{2}{*}{ Peer Norms*SOC } & -.110 & $(-.27, .05)$ & -.032 & .001 \\
\hline & & & & $\begin{array}{c}R^{2}=.047 * \\
\Delta R^{2}=.001\end{array}$ \\
\hline
\end{tabular}

Note: Dependent variable is Bystander Intervention Behavior; $r^{2}$ is the partial correlation squared 
Table 5.

Moderating Effects of Sense of Community (SOC) with Perceptions of Admin. Response

\begin{tabular}{|c|c|c|c|c|}
\hline Predictor & $b$ & $\begin{array}{c}95 \% \mathrm{CI} \\
(\mathrm{LL}, \mathrm{UL})\end{array}$ & $\beta$ & $r^{2}$ \\
\hline (Intercept) & $2.642 *$ & $(2.56,2.73)$ & & \\
\hline Living On Campus & $.194 *$ & $(.05, .34)$ & .064 & .004 \\
\hline Gender Male & $-.354 *$ & $(-.51,-.20)$ & -.109 & .011 \\
\hline Gender non-binary/undisclosed & $.364^{*}$ & $(.07, .66)$ & .059 & .003 \\
\hline Peer Norms & $-.412 *$ & $(-.57,-.25)$ & -.123 & .015 \\
\hline Perceived Admin. Resp. & $-.098 *$ & $(-.17,-.03)$ & -.074 & .004 \\
\hline SOC & .062 & $(-.03, .15)$ & .037 & .001 \\
\hline Perceived Admin Resp*SOC & .036 & $(-.03, .11)$ & .025 & .001 \\
\hline
\end{tabular}

Note: Dependent variable is Bystander Intervention Behavior; $r^{2}$ is the partial correlation squared 
Table 6.

Relation of Study Variables to Bystander Intervention Scale N/A responses

\begin{tabular}{lcccc}
\hline Predictor & $b$ & $95 \%$ CI & & \\
(Intercept) & $1.723^{*}$ & $(1.590,1.860)$ & & $r^{2}$ \\
Living On Campus & $-.352^{*}$ & $(-.593,-.112)$ & -.068 & .003 \\
Gender Male & -.033 & $(-.294, .229)$ & -.006 & .000 \\
Gender non-binary/undisclosed & .053 & $(-.435, .540)$ & .005 & .000 \\
Peer Norms & $-.640^{*}$ & $(-.923,-.357)$ & -.106 & .012 \\
Perceived Admin. Resp. & .012 & $(-.108, .131)$ & .005 & .000 \\
SOC & .001 & $(-.151, .152)$ & .000 & .000 \\
Bystander Behavior & $.450^{*}$ & $(.369, .531)$ & .263 & .068 \\
& & & & $R^{2}=.090^{*}$ \\
\hline
\end{tabular}

Note: Dependent variable is Number of N/A responses to Bystander Scale; $r^{2}$ is the partial correlation squared 


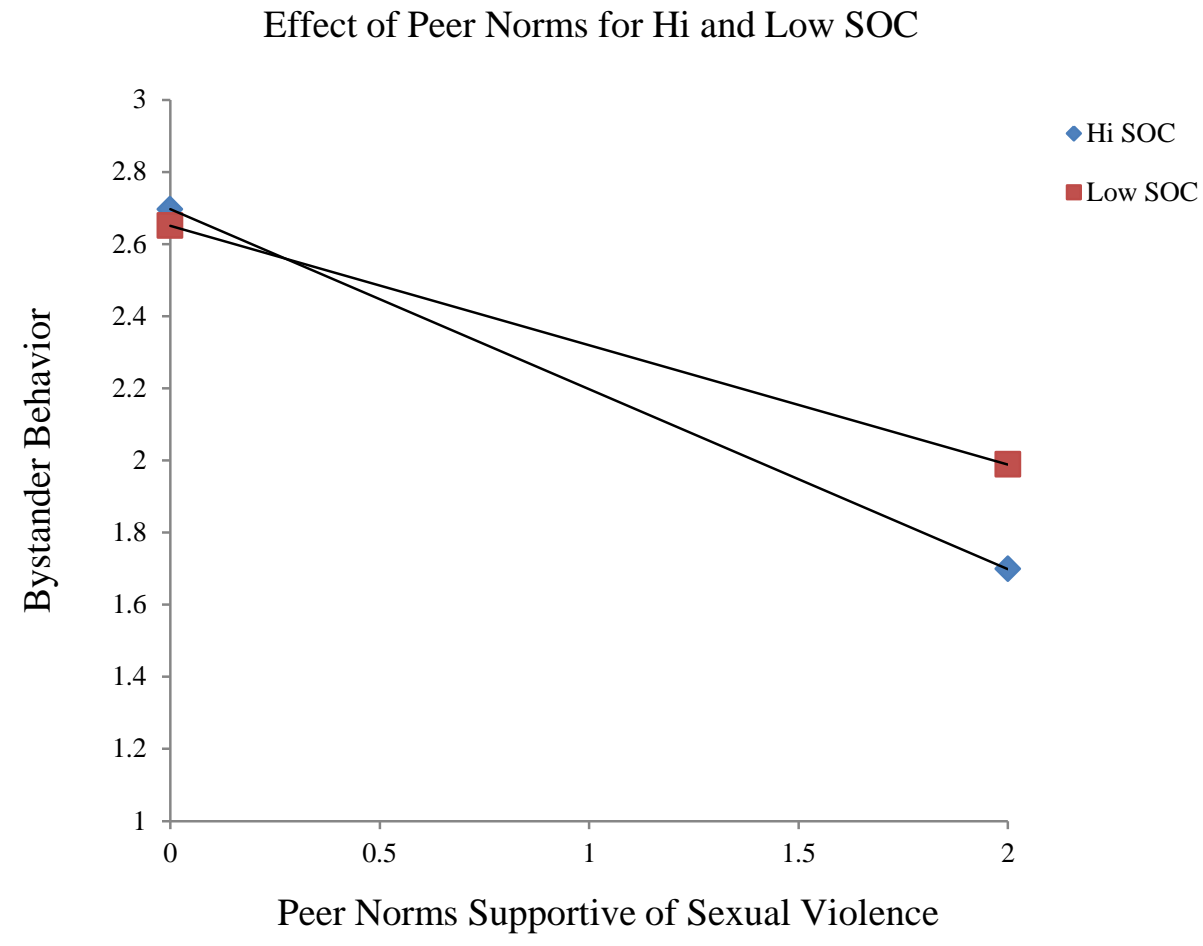

Figure 1. Effect of Peer Norms on Bystander Behavior for Hi and Low sense of community (SOC) Note: Lines represent expected bystander behavior scores when SOC is one standard deviation above and below the mean 


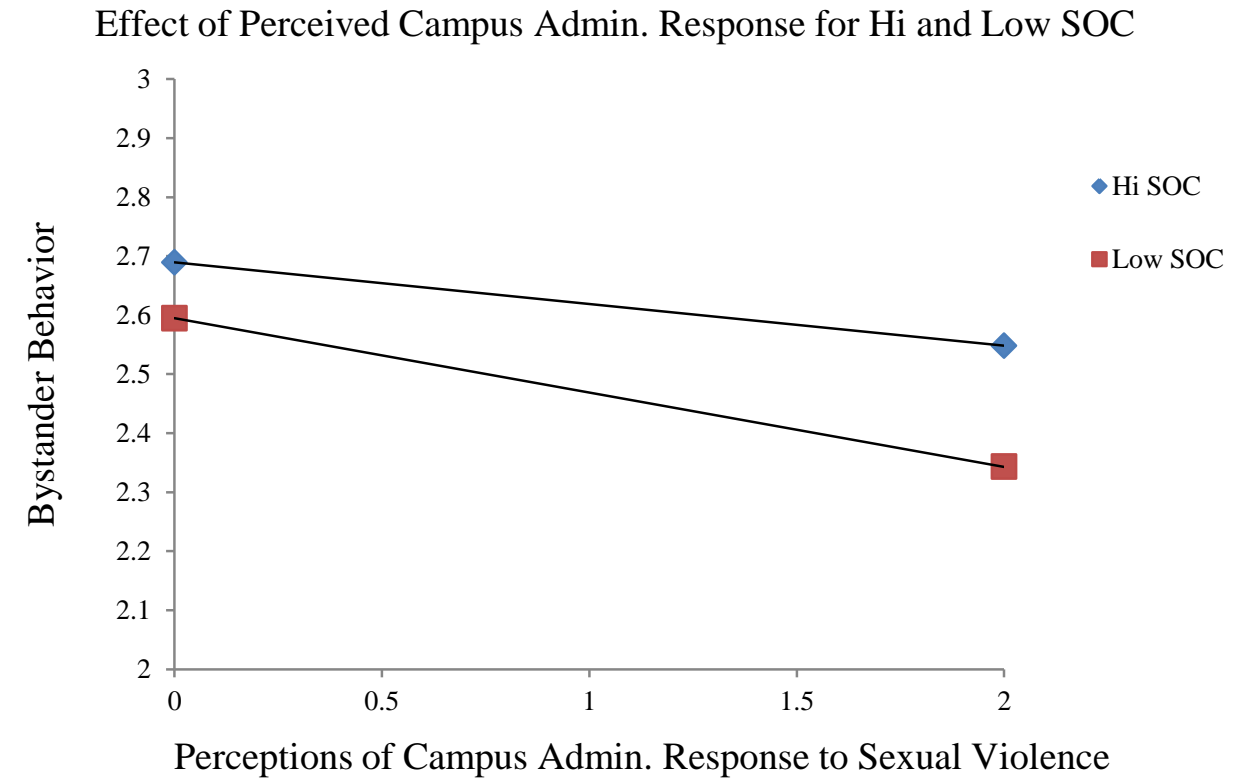

Figure 2. Effect of Perceived Campus Administrative Response for Hi and Low sense of community (SOC) Note: Lines represent expected bystander behavior scores when SOC is one standard deviation above and below the mean 


\section{References}

Azjen, I. (1988). Attitudes, personality and behavior. Milton Keynes, England: Open University Press

Ajzen, I. \& Fishbein, M. (1980). Understanding attitudes and predicting social behavior. Englewood Cliffs, NJ: Prentice-Hall.

ARC3 (n.d.) ARC3 Home. Retrieved April 8, 2018 from http://campusclimate.gsu.edu/

Baker, C. W., Little, T. D., \& Brownell, K. D. (2003). Predicting adolescent eating and activity behaviors: The role of social norms and personal agency. Health Psychology, 22(2), 189.

Banyard, V. L. (2008). Measurement and correlates of prosocial bystander behavior: The case of interpersonal violence. Violence and victims, 23(1), 83.

Banyard, V. L. (2011). Who will help prevent sexual violence: Creating an ecological model of bystander intervention. Psychology of violence, 1(3), 216.

Banyard, V. L. (2015). The promise of a bystander approach to violence prevention. In Toward the Next Generation of Bystander Prevention of Sexual and Relationship Violence (pp. 7-23). Springer International Publishing.

Banyard, V. L., \& Moynihan, M. M. (2011). Variation in bystander behavior related to sexual and intimate partner violence prevention: Correlates in a sample of college students. Psychology of Violence, 1(4), 287. 
Banyard, V., Moynihan, M., \& Plante, E. (2007). Sexual violence prevention through bystander education: An experimental evaluation. Journal of Community Psychology, 35(4), 463-481.

Banyard, V., Plante, E.., \& Moynihan, M. (2004). Bystander education: Bringing a broader community perspective to sexual violence prevention. Journal of Community Psychology, 32(1), 61-79.

Bennett, S., Banyard, V. L., \& Garnhart, L. (2014). To act or not to act, that is the question? Barriers and facilitators of bystander intervention. Journal of interpersonal violence, 29(3), 476-496.

Berkowitz, A. (2010). Fostering healthy norms to prevent violence and abuse: The social norms approach. . In Kaufman, K. (Eds.), The Prevention of Sexual Violence (147-169). NEARI Press

Bhargava, A., \& Jackson, G. (2013, May 9). Re: DOJ Case No. DJ169-44-9, OCR Case No. 10126001 (University of Montana). Washington, DC: U.S. Department of Education, Office for Civil Rights.

Black, M. C., Basile, K. C., Breiding, M. J., Smith, S. G., Walters, M. L., Merrick, M. T., ... Stevens, M. R. (2011). National intimate partner and sexual violence survey. Atlanta, GA: CDC.

Borja, S. E., Callahan, J. L., \& Long, P. J. (2006). Positive and negative adjustment and social support of sexual assault survivors. Journal of Traumatic Stress, 19(6), 905-914. 
Brodsky, A. (1996). Resilient single mothers in risky neighborhoods: Negative psychological sense of community. Journal of Community Psychology, 24(4), 347-363.

Brown, A., Banyard, V. L., \& Moynihan, M. M. (2014). The impact of perceived peer norms and gender, age, and race on bystander intentions and behaviors related to sexual violence. Psychology of Women Quarterly, 38, 350-362.

Brown, A., \& Messman-Moore, T. (2010). Personal and perceived peer attitudes supporting sexual aggression as predictors of male college students' willingness to intervene against sexual aggression. Journal of Interpersonal Violence, 25(3), 503-517.

Burn, S. (2009). A situational model of sexual assault prevention through bystander intervention. Sex Roles, 60(11), 779-792.

Cantor, D., Fisher, B., Chibnall, S., Townsend, R., Lee, H., Bruce, C., \& Thomas, G. (2015). Report on the AAU Campus Climate Survey on Sexual Assault and Sexual Misconduct. Westat, Rockville, MD.

CDC. (2014). Preventing sexual violence on college campuses: Lessons from research and practice. Retrieved April 13, 2017 from https://www.notalone.gov/schools/.

Cialdini, R. B., \& Trost, M. R. (1998). Social influence: Social norms, conformity, and compliance. In D. T. Gilbert, S. T. Fiske, \& G. Lindzey (Eds.), The handbook of social psychology (4th ed., Vol. 2, pp. 151- 192). Boston: McGraw-Hill. 
Coker, A. L., Bush, H. M., Fisher, B. S., Swan, S. C., Williams, C. M., Clear, E. R., \& DeGue, S. (2016). Multi-college bystander intervention evaluation for violence prevention. American Journal of Preventive Medicine, 50(3).

DeKeseredy, W.S., \& Kelly, K. (1995). Sexual abuse in Canadian university and college dating relationships: The contribution of male peer support. Journal of Family Violence, 10, 41- 53.

DeKeseredy, W. S., Schwartz, M. D., \& Alvi, S. (2000). The role of profeminist men in dealing with woman abuse on the Canadian college campus. Violence Against Women, 6(9), 918-935.

Edwards, K. M., Mattingly, M. J., Dixon, K. J., \& Banyard, V. L. (2014). Community matters: Intimate partner violence among rural young adults. American Journal of Community Psychology, 53(1-2), 198-207.

Fabiano, P. M., Perkins, H. W., Berkowitz, A., Linkenbach, J., \& Stark, C. (2003). Engaging men as social justice allies in ending violence against women: Evidence for a social norms approach. Journal of American College Health, 52(3), 105-112.

Fenton, R. A., Mott, H. L., McCartan, K. and Rumney, P. (2016) A review of evidence for bystander intervention to prevent sexual and domestic violence in universities. Technical Report. Public Health England. Retrieved from: http://eprints.uwe.ac.uk/28656

Fisher, B. S., Cullen, F. T., \& Turner, M. G. (2000). The sexual victimization of college women. Washington, DC: National Institute of Justice and Bureau of Justice Statistics. 
Foubert, J., Tabachnick, J., \& Schewe, P. (2010). Encouraging bystander intervention for sexual violence prevention. In Kaufman, K. (Eds.), The Prevention of Sexual Violence (121-134). NEARI Press

Gartner, R., \& Sterzing, P. (2016). Gender microaggressions as a gateway to sexual harassment and sexual assault. Affilia, 31(4), 491-503.

Golding, J. M. (1999). Sexual assault history and long-term physical health problems: Evidence from clinical and population epidemiology. Current Directions in Psychological Science, 8, 191-194.

Groff, E. R. (2015). Informal social control and crime events. Journal of Contemporary Criminal Justice, 31(1), 90-106.

Hayes, A. F., \& Cai, L. (2007). Using heteroskedasticity-consistent standard error estimators in OLS regression: An introduction and software implementation. Behavior Research Methods, 39(4), 709-722.

Hektner, J. M., \& Swenson, C. A. (2012). Links from teacher beliefs to peer victimization and bystander intervention: Tests of mediating processes. The Journal of Early Adolescence, 32(4), 516-536.

IBM Corporation (2016). IBM SPSS Statistics 24. IBM. Armonk, NY: IBM Corporation.

Kandel, D. (1973). Adolescent marihuana use: Role of parents and peers. Science, 181(4104), 1067-1070.

Koss, M. P., Wilgus, J. K., \& Williamsen, K. M. (2014). Campus sexual misconduct: Restorative justice approaches to enhance compliance with Title IX guidance. Trauma, Violence, \& Abuse, 15(3), 242-257. 
Krug, E. G., Mercy, J. A., Dahlberg, L. L., Zwi, A. B., \& Lozano, R. (2002). The world report on violence and health. The lancet, 360(9339), 1083-1088.

Lapinski, M., \& Rimal, R. (2005). An explication of social norms. Communication Theory, 15(2), 127-147.

Latané, B., \& Darley, J. M. (1970). Social determinants of bystander intervention in emergencies. Altruism and Helping Behavior, 13-27.

Lounsbury, J. W., \& DeNeui, D. (1996). Collegiate psychological sense of community in relation to size of college/university and extroversion. Journal of Community Psychology, 24(4), 381-394.

Luca, M., Rooney, P., \& Smith, J. (2016). The impact of campus scandals on college applications. Harvard Business School (working paper).

Mannarini, T., \& Fedi, A. (2009). Multiple senses of community: The experience and meaning of community. Journal of Community Psychology, 37(2), 211227.

Mengo, C., \& Black, B. M. (2016). Violence victimization on a college campus: Impact on GPA and school dropout. Journal of College Student Retention: Research, Theory \& Practice, 18(2), 234-248.

McLaughlin, C., Arnold, R., \& Boyd, E. (2005). Bystanders in schools: What do they do and what do they think? Factors influencing the behaviour of English students as bystanders. Pastoral Care in Education, 23(2), 17-22.

McMahon, S. (2015). Call for research on bystander intervention to prevent sexual violence: The role of campus environments. American Journal of Community Psychology, 55(3-4), 472-489. 
McMahon, S., \& Banyard, V. (2012). When can I help? A conceptual framework for the prevention of sexual violence through bystander intervention. Trauma, Violence, \& Abuse, 13(1), 3-14.

McMahon, S., Palmer, J., Banyard, V., Murphy, M., \& Gidycz, A. (2017). Measuring bystander behavior in the context of sexual violence prevention: Lessons learned and new directions. Journal of Interpersonal Violence, 32(16).

McMahon, S., Postmus, J., \& Koenick, R. (2011). Conceptualizing the engaging bystander approach to sexual violence Prevention on College Campuses. Journal of College Student Development, 52(1), 115-130.

McMahon, S., Stepleton, K., \&. Cusano, J. (2016). Understanding and responding to campus sexual assault: A guide to climate assessment for colleges and universities. Center on Violence Against Women and Children, Rutgers School of Social Work: New Brunswick, NJ.

McMillan, D. W., \& Chavis, D. M. (1986). Sense of community: A definition and theory. Journal of Community Psychology, 14(1), 6-23.

Moynihan, M., Banyard, V., Cares, A., Potter, S., Williams, L., \& Stapleton, J. (2015). Encouraging responses in sexual and relationship violence prevention. Journal of Interpersonal Violence, 30(1), 110-132.

Nelson, G. \& Prilleltensky, I. (2005). Community Psychology: In Pursuit of Liberation and Well-Being. New York: Palgrave MacMillan. 
New, J. (2016) Creating the right campus climate survey. Inside Higher Ed.

Retrieved April 8, 2018 from

https://www.insidehighered.com/news/2016/07/29/campus-climate-surveysabound-does-disagreement-over-what-works-best

New York State Department of Health (2013). Stop sexual violence: A sexual violence bystander intervention toolkit. Retrieved from https://www.health.ny.gov/publications/2040.pdf

Orchowski, L. M., Berkowitz, A., Boggis, J., \& Oesterle, D. (2016). Bystander intervention among college men: The role of alcohol and correlates of sexual aggression. Journal of interpersonal violence, 31(17), 2824-2846.

Peterson, N. A,, Speer, P. W., \& McMillan, D. W. (2008). Validation of a brief sense of community scale: Confirmation of the principal theory of sense of community. Journal of Community Psychology, 36(1), 61-73.

Planty, M. (2002). Third-party involvement in violent crime, 1993-1999. National Institute of Justice, Bureau of Justice Statistics Special Report. Rockville, MD. Justice Statistics Clearinghouse/NCJRS. NCJ 189100

Portland State University (2016). Sexual misconduct campus climate survey report. Retrieved from: https://www.pdx.edu/diversity/sites/www.pdx.edu.diversity/files/campuscli matesurvey\%20final\%20report_0.pdf

Powell, A. (2011) Review of bystander approaches in support of preventing violence against women [online]. Victoria, New South Wales: Victoria Health Promotion Foundation. Publication P-052-V B. Retrieved from: 
http://www.ncdsv.org/images/VicHealth_ReviewBystanderApproachesSup portPreventing VAW_5-2011.pdf

Sarason, S (1974) Psychological sense of community: Prospects for a community psychology. San Francisco, CA: Jossey Bass.

Scalici, F., \& Schulz, P. J. (2017). Parents' and peers' normative influence on adolescents' smoking: results from a Swiss-Italian sample of middle schools students. Substance Abuse Treatment, Prevention, and Policy, 12(1), 5.

Schwartz, M. D., \& DeKeseredy, W. (1997). Sexual assault on the college campus: The role of male peer support. Sage Publications.

Schwartz, M. D., DeKeseredy, W. S., Tait, D., \& Alvi, S. (2001). Male peer support and a feminist routing activities theory: Understanding sexual assault on the college campus. Justice Quarterly, 18(3), 623-649.

Senn, C. Y., \& Forrest, A. (2015). 'And then one night when I went to class . . .': The impact of sexual assault bystander intervention workshops incorporated in academic courses. Psychology of Violence, 1, 1-12.

Stein, J. L. (2007). Peer educators and close friends as predictors of male college students' willingness to prevent rape. Journal of College Student Development, 48(1), 75-89.

Storer, H. L., Casey, E. A., \& Herrenkohl, T. I. (2017). Developing “whole school” bystander interventions: The role of school-settings in influencing adolescents responses to dating violence and bullying. Children and youth services Review, 74, 87-95. 
Sulkowski, M. (2011). An investigation of students' willingness to report threats of violence in campus communities. Psychology of Violence, 1(1), 53-65.

Taylor, S., \& Todd, P. A. (1995). Understanding information technology usage: A test of competing models. Information Systems Research, 6(2), 144-176.

Turchik, J. A., \& Hassija, C. M. (2014). Female sexual victimization among college students: Assault severity, health risk behaviors, and sexual functioning. Journal of Interpersonal Violence, 29(13), 2439-2457.

Ullman, S., \& Brecklin, L. (2003). Sexual assault history and health-related outcomes in a national sample of women. Psychology of Women Quarterly, 27(1), 46-57.

United Educators (2015). The high cost of student-victim sexual assault claims. A report by Canopy Programs. Retrieved February 22nd from https://static1.squarespace.com/static/53e530a1e4b021a99e4dc012/t/59050 1f74402431ac4900596/1493500411575/FN-+RE-+2017.04+ High + Cost+of + Student-Victim + SA+Claims.pdf 
Appendix A. Measures

Bystander intervention behaviors (adapted from Banyard, 2008)

Instructions: When the situation arose while enrolled at PSU, how often did you do any of the following?

\begin{tabular}{|c|c|c|c|c|c|c|}
\hline & Never & Sometimes & $\begin{array}{l}\text { A Few } \\
\text { Times }\end{array}$ & $\begin{array}{l}\text { Most of } \\
\text { the } \\
\text { time }\end{array}$ & Always & N/A \\
\hline $\begin{array}{l}\text { Walked a friend who } \\
\text { has had too much to } \\
\text { drink home from a } \\
\text { party, bar, or other } \\
\text { social event. }\end{array}$ & ○ & $\bigcirc$ & O & O & 0 & O \\
\hline $\begin{array}{l}\text { Talked to the friends of } \\
\text { a drunk person to make } \\
\text { sure they don't leave } \\
\text { him/her behind at a } \\
\text { party, bar, or other } \\
\text { social event. }\end{array}$ & 0 & ○ & O & 0 & 0 & ○ \\
\hline $\begin{array}{l}\text { Spoke up against sexist } \\
\text { or sexually suggestive } \\
\text { jokes. }\end{array}$ & O & O & O & O & $\bigcirc$ & ○ \\
\hline \multirow{2}{*}{$\begin{array}{l}\text { Tried to distract } \\
\text { someone who was } \\
\text { trying to take a drunk } \\
\text { person to another room } \\
\text { or trying to get them to } \\
\text { do something sexual. }\end{array}$} & 0 & 0 & 0 & 0 & 0 & 0 \\
\hline & Never & Sometimes & $\begin{array}{l}\text { A Few } \\
\text { Times }\end{array}$ & $\begin{array}{l}\text { Most of } \\
\text { the } \\
\text { time }\end{array}$ & Always & N/A \\
\hline $\begin{array}{l}\text { If you are still reading } \\
\text { this survey choose, "A } \\
\text { few times." }\end{array}$ & ○ & ○ & 0 & ○ & ○ & ○ \\
\hline $\begin{array}{l}\text { Ask someone who looks } \\
\text { very upset at a party if } \\
\text { they are okay or need } \\
\text { help. }\end{array}$ & ○ & ○ & 0 & ○ & 0 & 0 \\
\hline $\begin{array}{l}\text { Intervene with a friend } \\
\text { who was being } \\
\text { physically abusive to } \\
\text { another person. }\end{array}$ & O & O & ○ & O & 0 & $\bigcirc$ \\
\hline $\begin{array}{l}\text { Intervene with a friend } \\
\text { who was being verbally } \\
\text { abusive to another } \\
\text { person. }\end{array}$ & 0 & 0 & 0 & 0 & 0 & O \\
\hline
\end{tabular}


Sense of Campus Community (adapted from Peterson, Speer \& McMillan, 2008)

Please indicate the extent to which you agree or disagree with the following statements about your PSU community.

\begin{tabular}{|c|c|c|c|c|c|}
\hline & $\begin{array}{l}\text { Strongly } \\
\text { Disagree }\end{array}$ & Disagree & Neutral & Agree & $\begin{array}{c}\text { Strongly } \\
\text { Agree }\end{array}$ \\
\hline $\begin{array}{l}\text { I can get what I } \\
\text { need in this campus } \\
\text { community. }\end{array}$ & 0 & 0 & 0 & 0 & 0 \\
\hline $\begin{array}{l}\text { This campus } \\
\text { community helps } \\
\text { me fulfill my needs. }\end{array}$ & ○ & 0 & 0 & 0 & 0 \\
\hline $\begin{array}{l}\text { I feel like a } \\
\text { member of this } \\
\text { campus } \\
\text { community. }\end{array}$ & 0 & 0 & 0 & 0 & ○ \\
\hline \multirow{2}{*}{$\begin{array}{l}\text { I belong in this } \\
\text { campus } \\
\text { community. }\end{array}$} & 0 & $\bigcirc$ & $\bigcirc$ & $\bigcirc$ & $\bigcirc$ \\
\hline & $\begin{array}{l}\text { Strongly } \\
\text { Disagree }\end{array}$ & Disagree & Neutral & Agree & $\begin{array}{c}\text { Strongly } \\
\text { Agree }\end{array}$ \\
\hline $\begin{array}{l}\text { I have a say about } \\
\text { what goes on in my } \\
\text { campus } \\
\text { community. }\end{array}$ & 0 & 0 & 0 & 0 & 0 \\
\hline $\begin{array}{l}\text { People in this } \\
\text { campus community } \\
\text { are good at } \\
\text { influencing each } \\
\text { other. }\end{array}$ & 0 & 0 & 0 & 0 & 0 \\
\hline $\begin{array}{l}\text { I feel connected to } \\
\text { this campus } \\
\text { community. }\end{array}$ & 0 & 0 & 0 & 0 & 0 \\
\hline $\begin{array}{l}\text { I have a good bond } \\
\text { with others in this } \\
\text { campus } \\
\text { community. }\end{array}$ & 0 & 0 & 0 & 0 & 0 \\
\hline
\end{tabular}


Peer Norms Supportive of Sexual Violence (adapted from DeKeseredy \& Kelly, 1995)

Instructions: Indicate how much you agree or disagree with each statement below:

$\begin{array}{lllll}\begin{array}{l}\text { Strongly } \\ \text { Disagree }\end{array} & \text { Disagree } & \text { Neutral } & \text { Agree } & \begin{array}{c}\text { Strongly } \\ \text { agree }\end{array}\end{array}$

My friends would approve of forcing someone to have sex.

My friends would approve of getting someone drunk or high to have sex with them.

My friends would approve of lying to someone in order to have sex with them.

My friends tell me that someone you are dating should have sex with you when you want.

My friends tell me that when you spend money on a date, the person should have sex with you in return.

My friends tell me that it is alright to non consensually physically force a person to have sex under certain conditions. 


\section{Campus Administrative Responsiveness (ARC3)}

The following are statements about what might happen if someone were to report a sexual assault or sexual misconduct to the Title IX Coordinator/Office of Equity \& Compliance (OEC) or Office of the Dean of Student Life (DOSL) at PSU. Please use the scale provided to indicate how likely you think each scenario is.

$\begin{array}{llll}\text { Not } & & \\ \text { at A } & & \\ \text { All little Somewhat Very Extremely }\end{array}$

How likely is it that PSU administrators would take the report seriously?

How likely is it that PSU administrators would protect the safety of the person making the report?

How likely is it that PSU administrators would conduct a fair investigation?

How likely is it that PSU administrators would take action against the offender(s)?

How likely is it that PSU administrators would take action to address factors that may have led to the sexual assault or sexual misconduct?

Not

at A

All little Somewhat Very Extremely

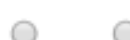

$\bigcirc$

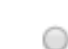

(1)

0
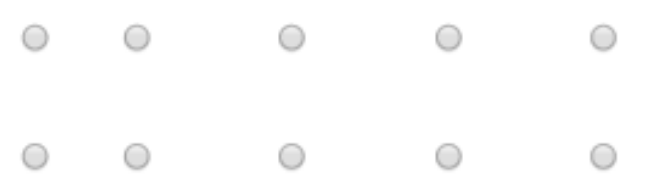

0

sexual misconduct? 